\title{
THE EFFECTS OF MICROWAVE RADIATION
}

ON EGGS, EMBRYOS

AND CHICKENS

A THESIS

PRESENTED TO

THE FACULTY OF GRADUATE STUDIES AND RESEARCH

THE UNIVERSITY OF MANITOBA

IN PARTIAL FULFILLIMENT

OF THE REQUIREMENTS FOR THE DEGREE

MASTER OF SCIENCE

BY

John A. Davidson

Nay 1974 


\section{ACKNOWLEDGENENTS}

The author is indebted to Dr. P. A. Kondra for providing the opportunity to carry out this research and for his guidance and criticism.

Appreciation is also expressed for the criticism and guidance of Dr. M. A. Hamid, Dr. G. D. Phillips and Professor G. C. Hodgson.

The author greatly appreciates the assistance given by Dr. J. M. Neufeld and the staff of the Provincial Veterinary Pathology Laboratory and by Steve Antonation and his staff.

The technical guidance of Mr. No Mostowy of the Department of Electrical Engineering is also appreciated. 
The Effects of Microwave Radiation

on Eggs, Embryos and Chickens

John A. Davidson

ABSTRACT

Experiments were conducted to determine the effects of exposing eggs, embryos and live chicks to high density microwave irradiation.

Fertile eggs and embryos at 1 or 2 days of incubation were exposed to a range of 66 to 75 watts of power input per egg for durations ranging from 10 to 350 seconds. Irradiation dose below that which caused thermal changes, such as coagulation of egg constitutents (i.e. 75 watts per egg for $45 \mathrm{sec}$ )), had no effect on embryo development, hatchability, post embryonic growth of chicks, sanitizing of eggs or their keeping quality. Similar irradiation of live chicks with an energy dose below that which caused visible thermal tissue damage (i.e. 600 watt-sec. input per chick) had no effect on growth of such chicks to maturity or their reproductive performance. It was observed that 800 watt-sec. per chick was a lethal dose.

This lethal dose corresponds to a lethal density of $1 \mathrm{w} / \mathrm{cm}^{2}$ for 9 seconds. If we set the safe exposure level at $1 / 1000$ the lethal dose this gives a safe dose for chicks of $1 \mathrm{mw} / \mathrm{cm}^{2}$ for 9 seconds. This is comparable to the safe dose for humans. 


\section{ABSTRACT}

Experiments were conducted to determine the effects of exposing eggs, embryos and live chicks to high density microwave irradiation.

Fertile eggs and embryos at 1 or 2 days of incubation were exposed to a range of 66 to 75 watts of power input per egg for durations ranging from 10 to 350 seconds. Irradiation dose below that which caused thermal changes, such as coagulation of egg constitutents (i.e. 75 watts per egg for $45 \mathrm{sec}$ ), had no effect on embryo development, hatchability, post embryonic growth of chicks, sanitizing of eggs or their keeping quality.

Similar irradiation of live chicks with an energy dose below that which caused visible thermal tissue damage (i.e. 600 watt-sec. input per chick) had no effect on growth of such chicks to maturity or their reproductive performance. It was observed that 800 watt-sec. per chick was a lethal dose.

This lethal dose corresponds to a lethal density of $1 \mathrm{w} / \mathrm{cm}^{2}$ for 9 seconds. If we set the safe exposure level at $1 / 1000$ the lethal dose this gives a safe dose for chicks of $1 \mathrm{mw} / \mathrm{cm}^{2}$ for 9 seconds. This is comparable to the safe dose for humans. 
TABLE OF CONTENTS

Page

INTRODUCTION $\ldots \ldots \ldots \ldots \ldots \ldots \ldots \ldots \ldots \ldots \ldots \ldots \ldots$

IITERATURE REVIEW. ...................... 2

MATERIALS AND METHODS.................... 12

General Materials and Nethods............ 12

PREL IMINARY EXPERIMENTS ....................... 15

Preliminary Experiment 1............. 15

Preliminary Experiment 2............... 16

Preliminary Experiment $3 \ldots \ldots \ldots \ldots \ldots \ldots$

Preliminary Experiment $4 \ldots \ldots \ldots \ldots \ldots \ldots \ldots \ldots$

Preliminary Experiment $5 \ldots \ldots \ldots \ldots \ldots . . . . .17$

Experiment A.......................... 17

Experiment $B_{0} \ldots \ldots \ldots \ldots \ldots \ldots \ldots \ldots \ldots \ldots \ldots . \ldots \ldots$

Experiment C............................ 20

Experiment D.......................... 20

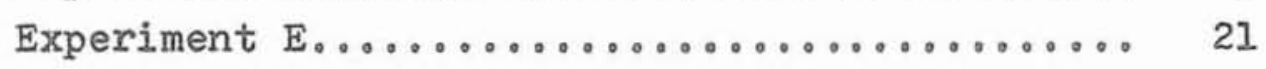

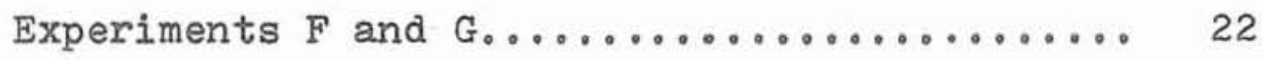

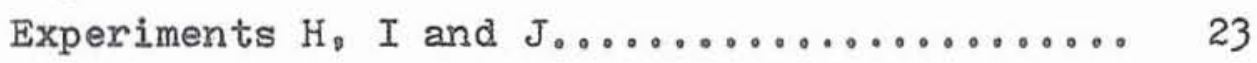

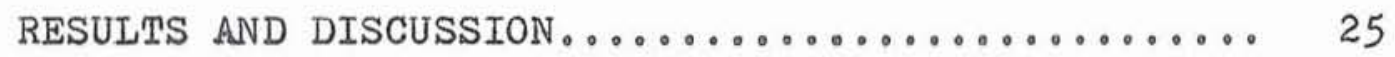

Preliminary Experiment $1 \ldots \ldots \ldots \ldots . \ldots \ldots 25$

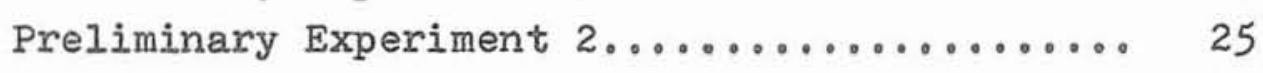

Preliminary Experiment $3 \ldots \ldots \ldots \ldots . \ldots \ldots 27$

Preliminary Experiments 4 and $5 \ldots \ldots \ldots 27$

Experiment A........................... 29

Experiment B............................ 31

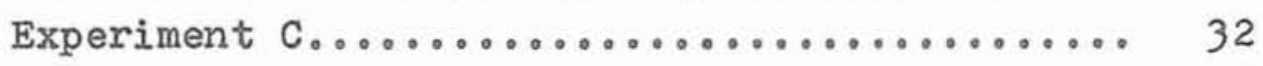

Experiment D.............................. 38

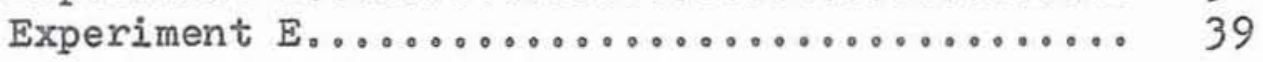

Experiments $F$ and $G_{0} \ldots \ldots \ldots \ldots \ldots \ldots \ldots . \ldots \ldots$

Experiments $H, I$, and $J \ldots \ldots \ldots \ldots \ldots . \ldots \ldots$ 
Page

CONCLUSIONS............................. 43

TABLES................................... 45

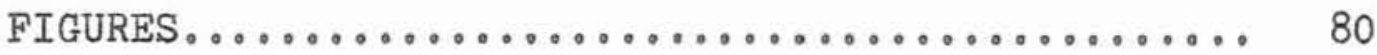

REFERENCES .............................. 82 


\section{INTRODUCTION}

In the last two decades electronic energy in the form of microwave power has become a significant tool in medical, industrial and domestic applications. The use of microwave generating equipment where exposure of animals and people to radiation is possible or even inevitable has led to questioning of the safety of prolonged, or repeated short exposure. The loudest wamings now come from consumer protection groups who question the safety of home appliances which utilize microwave power. In the past few years numerous experiments have been carried out to test the susceptability of biological materials to microwave radiation.

Research reported here involved some further tests on chick embryos irradiated with microwaves at different stages of development, but it extended to treatment of day old chicks which were subsequently grown to maturity and tested for reproductive performance, including the effect on their progeny. The effect of microwave treatment on sanitization of eggs and on their keeping quality was also investigated. 


\section{IITERATURE REVIEW}

For review of the propagation and properties of microwaves the reader is referred to Hills' (1971) report which will also be useful for an extensive review of the literature prior to 1970 .

Microwave radiation falls in the band of frequencies from roughly 300 to $300,000 \mathrm{MHz}$. This covers wavelengths from the millimeter through the meter range. Photon energies are approximately $10^{-5} \mathrm{eV}$ per photon. The wavelength range which is involved in physical hazards is the $1 \mathrm{~cm}$ to $100 \mathrm{~cm}$ range with frequencies between 300 and $30,000 \mathrm{MHz}$.

Power outputs of microwave medium and high power apparatus range from less than $100 \mathrm{w}$ (measured at the waveguide output) for medical diathermy uses to millions of watts for high power pulse radar sets. Exposures are generally measured and reported in one of two methods, by the power density, i.e. watts per square centimeter $\left(\mathrm{w} / \mathrm{cm}^{2}\right)$ or by power input, measured in watt seconds, which is a measure of the amount of electrical energy absorbed by the irradiated object.

One of the first, and subsequently most investigated phenomena associated with microwaves is cataractogenesis. Milroy and Michaelson (1972) state "Currently it would appear that the production of lenticular opacities is the most significant hazard associated with microwave 
irradiation, at least in American investigations".

In recent experimentation attention has been focused on the "whole body" effects of microwaves with various phenomena being attributed to irradiation with microwaves. McAfee et al. (1958) reported increased growth rates in mice exposed to periodic daily treatment with $10 \mathrm{~cm}$ microwave irradiation, $(2450 \mathrm{MHz}$ at a flux of $\left.10 \mathrm{mw} / \mathrm{cm}^{2}\right)$. This claim was later refuted by McAfee et al. (1973) after careful examinations of the material and repeating the experiment.

Kondra et al. (1970) reported that birds subjected to continuous low level irradiation at either .02 or 400 picowatts $/ \mathrm{cm}^{2}$ from day to hatch to 476 days had higher average egg production and increased feed efficiency over control birds. Peak egg production was also higher in the irradiated birds. It was reported that the effect of microwave irradiation was only to increase frequency of ovulation as manifested by increased rate of lay, possibly through the stimulation of the pituitary. Hatchability, water consumption and interior egg quality were not affected by the treatments. Kondra et al. (1970) concluded that continuous microwave radiation was not harmful and might have some beneficial effects . Kondra et al. (1972) repeated the experiment described above. Results of this second experiment showed 
no significant differences in body weights at 8 and 20 weeks of age, feed efficiency for growth, feed efficiency for egg production and egg production.

It was concluded that continuous exposure to microwaves, even at a density of 400 picowatts $/ \mathrm{cm}^{2}$ which is 20,000 times that occurring in the immediate vicinity of a typical microwave transmissions tower, will have minimal, if any, effects on laying chickens.

Hills (1971) also using continuous wave microwaves continued research on the same line and concluded that the birds were not influenced by radiation treatments. Romero-Sierra and Tanner (1970) found results similar to those of Kondra et al. (1970). The former studies found that following treatment with pulsed irradiation with densities from $0.18 \mathrm{mw} / \mathrm{cm}^{2}$ to $360 \mathrm{mw} / \mathrm{cm}^{2}$ the egg production of the treated hens increased by $13.7 \%$. They concluded that microwaves have a profound effect on the egg production of chickens.

Van Ummerson (1963) irradiated chick embryos incubated at $39^{\circ} \mathrm{C}$ to approximately the 48 hour stage of development at a level of $400 \mathrm{mw} / \mathrm{cm}^{2}$. After irradiation eggs were allowed to continue development for 48 hours 
at which time they were removed and examined. She noted that of 366 eggs exposed to irradiation 103 embryos died and a further 19 showed evidence of interference in development. Anomalies fell into two catagories. 1) General inhibitory effects, in which small body size was the most obvious effect. The brain had not progressed past the 48 hour stage. Eyes were atypical in shape and abnormally small. Wing buds were either absent or abnormally small. Hind limb development was supressed in almost all embryos. The hearts showed no evidence of partitioning into four chambers and the myocardium was extremely thin. Neither allantois nor tail bud had developed. 2) Posterior inhibitory effects which usually resulted in embryos showing defects only posterior to the wing bud. The anterior portion was normal for a 96 hour embryo but the posterior part of the body was lacking. Van Ummerson (1963) concluded that microwave radiation appears to inhibit cellular differentiation in the developing chick embryo.

Hills (1971) conducted experiments in which embryos were irradiated with both high and low levels of $\mathrm{cw}$ microwaves during the incubation period. A series of experiments were conducted, the first of these consisting of four experiments, involved exposure of chick embryos to low density irradiation at different stages of incubation. The second series of experiments involved exposure of eggs at 1 or 2 days of incubation, to higher 
density microwaves ranging from 0.051 to $1.02 \mathrm{w} / \mathrm{cm}^{2}$ at a frequency of $2450 \mathrm{MHz}$ for various lengths of exposure.

In the low density experiments hatchability, body weight at hatching and at two weeks of age as well as feed efficiency and mortality during this period, were not significantly affected by microwave treatment. However, in the high density experiments, irradiation at a density of $1.02 \mathrm{w} / \mathrm{cm}^{2}$ resulted in reduced hatchability and body weight at hatching, the severity of which increased with length of exposure and advancing stage of incubation. In these treatments at 1 or 2 days of incubation the lethal effect was reached within a microwave density range of 0.123 and $0.246 \mathrm{w} / \mathrm{cm}^{2}$, with exposure of 90 seconds or more, the 2 day embryos being more sensitive.

Many studies have been done on live animals to ascertain the effects of microwaves on the body. Tanner (1966), and Tanner et al. (1967 and 1969) conducted research on avian species with the aim of finding a method of controlling bird flight near airports. Tanner (1966) reported that sustained extensor muscle activity of a wing and leg occurred during pulsed irradiation. Selective shielding of either head or body had no effect on the reaction. 0ld English Game species chicks at 10 days of age, exposed to pulsed $16 \mathrm{GHz}$ field with a density of $20 \mathrm{mw} / \mathrm{cm}^{2}$ were observed to become weak and/or collapsed upon irradiation. A state of panting was induced which 
persisted for a short while after the field was removed. Agitation and panting were observed in most birds exposed to radiation. Tanner concluded that the escape reaction (agitation) may be attributable not only to the heating effect produced but also to other mechanisms such as electromagnetic interaction with nerve structures, molecular resonance, or chemical excitation.

The question arises as to what caused the various effects noted to occur during periods of microwave irradiation. McAfee (1972) reported that ozone and oxides of nitrogen are generated by microwave equipment. These products are a result of ionizing radiation such as soft $\mathrm{X}$-rays and $\mathrm{U} \cdot \mathrm{V}$. radiation emitted by the magnetron. MicAfee suggested that many of the effects attributed to microwaves in early papers might have been due to these phenomena. Many of the so-called "non-thermal" effects reported in early papers were probably caused by thermal effect on short sections of nerves. When subcutaneous temperature reaches $45^{\circ} \mathrm{C} \pm 2^{\circ} \mathrm{C}$ and short lengths of the nerve are also heated a nociceptive response is produced. This response includes arousal of anesthesized animals. changes in blood pressure and respiration, and effects on the endocrine system.

Milroy and Michaelson (1971) report motor paralysis in small animals which terminates when exposure stops. They suggest this may be a resonant effect on the electrical conduction of nerves. Milroy and Michaelson (1971) 
believe "whole body" effects produced by microwaves are essentially those of heating. Hyperpyrexia is produced when thermoregulatory capacity is exceeded. The physiological response consists of acidosis, hyperpnea, lacrimation, tetany and finally death due to respiratory arrest. Pathological changes are similar to those found due to fever. A general congestion of the organs is noted in animals sacrificed prior to death after microwave irradiation. Direct thermal burns have been produced. The effect on animals irradiated at sublethal levels appear to be those typical of "stress syndrome" as a response to thermal hypothalmic-hypophyseal stimulation. Milroy and Michaelson (1971) report that this effect is expressed as a decrease in eosinophils and lymphocytes along with a rise in granulocytes.

While the investigation of thermal effects continues many believe that "non-thermal" or electromagnetic effects of microwaves exist. These effects must exist on the molecular level. Schwan (1972) defined a "non-thermal" effect as that which is caused by a biological response to a direct interaction between an electrical field and the cell or macromolecule affected. Non-thermal effects which are those caused by a biological response to a direct interaction between electrical field and the cell or macromolecule affected, can be strong or weak. Strong effects take place at field strength levels above $10 \mathrm{mw} / \mathrm{cm}^{2}$, while weak effects are 
those that occur at lower levels. Schwan concluded that present knowledge does not indicate the presence of such weak effects。

Pearl chain formation, the tendency for nonspherical particles to line up in a manner so as to maintain a state of minimum electrical potential energy in an induced field, has also been studied by Schwan (1972). Schwan concluded that pearl chain formations is of no particular biological significance from the point of view of microwave exposure hazards. Schwan also asked the question. "Is it possible that pulsed radiation can be more effective in bringing about biological changes than continuous radiation of the same average power?" By both theoretical and experimental means Schwan illustrated that pulsed fields are no more effective in causing biophysical changes than continuous fields of the same average power. Schwan (1969) denied that moleculax resonance is likely to occur in biological situations. This is in direct conflict with the previously reported theories of Tanner (1969). Schwan theorized that resonances are unlikely to occur because the macromolecules are suspended in electrolytes with high electrical losses which would dampen out any possible resonance.

Can microwaves cause any chemical changes in a biological system? To cause a chemical reaction the number of quanta of energy absorbed by a molecule simultaneously must be high enough to break an individual bond. $\mathrm{X}$-rays, 
gamma rays, ultraviolet light and in some cases, visible light have enough energy to break certain bonds (eg. 0.1 eV hydrogen bonds). Rosen (1972) reported that the quantum energies of microwaves fall short by several orders of magnitude of breaking chemical bonds. Therefore it is most improbable that microwaves would cause any chemical changes in a biological material. Rosen states that "so far no chemical reaction resulting from non-thermal microwave interaction has been described in any regular scientific paper, nor have any been confirmed by independent investigators". Rosen believed that thermal effects, either non-specific or of a more complex type, are sufficient explanation for most if not all actions of microwaves, even on living cells. Takashima (1969) stated that the delicate balance of extensive hydrogen bonded structures, which determines the functions of biological macromolecules including those which are the bearers of genetic information in the cells, are "possibly susceptible" to disturbances by microwaves. Janes et al. (1969) attempted to produce chromosomal abnormalities in mammals with $2450 \mathrm{MHz}$ radiation. This treatment did not increase the incidence of aberrations in the Chinese hamster.

Rosen (1972) concluded that until further evidence is available we must conclude that possible influences, other than thermal, are of no significance when biological macromolecular materials are heated with microwaves. 
One further area is open for investigation. This is the area of sterilization via microwaves. Conventional sterilization of eggs is ruled out due to the timetemperature levels required as given by Bilbrough (1969). Bilbrough stated that temperatures of $70^{\circ} \mathrm{C}$ for 20 minutes are usually required for sterilization of foodstuffs. Rapid heating by microwaves to $85^{\circ} \mathrm{C}$ for 10 to 20 seconds will reduce bacteria counts on meat from $138,000 / \mathrm{g}$ to $18,000 / \mathrm{g}$. In the poultry industry both of these levels are not usable due to the resulting thermal coagulation of the egg product. It would therefore appear that for our purposes the only hope for sterilization will be in previously undiscovered "non-thermal" effects or a previously untested time-temperature range for specific organisms。

Due to the limited amount of data available on the effects of microwave power on the chicken embryo, chicks, and eggs it was decided to conduct further experiments to determine the effects, if any, of microwave irradiation on embryos and newly hatched chicks. It was felt that further investigation of the data reported by Hills (1971), Tanner (1966), Tanner et al. (1969, 1970 and 1971), and Van Ummerson (1963) would be of value in further investigations of the biological effects of microwaves. 


\section{MATERIAIS AND METHODS}

A series of experiments were conducted to assess the effects of microwave irradiation on embryonic development, post-embryonic growth to maturity, egg production and livability of laying stock. Further experiments were conducted to determine the sanitizing and other effects of microwaves on market and hatching quality of eggs. These experiments will be designated as follows: Preliminary experiment with subsections 1 to 5 which involved treatment of chick embryos at various stages of development to a range of microwave power outputs (Tables 1-6) for varying lengths of time in order to determine maximum radiation tolerance.

Experiment $A$ in which eggs were exposed to the maximum radiation dose, would not result in thermal damage to the egg constituents. Experiments $1-5$ and A. utilized eggs from the University of Nanitoba laying flock Shaver Starcross \#288 stock.

In Experiment B newly hatched male chicks were irradiated with microwaves in order to establish the minimum lethal dose in a particular microwave chamber.

In Experiment $C$ newly hatched male chicks were exposed to two different sublethal doses of microwave radiation in order to observe the effects on subsequent growth. 
In Experiment D newly hatched female chicks exposed to a sublethal dose of microwave radiation according to previous tests were grown to 40 weeks of age.

Experiment $E$ was a replication of Experiment $D$ involving much greater numbers of pullets.

Experiments $F$ and $G$ were designed to study the effect of microwave irradiation on the keeping qualities of fresh eggs for human consumption.

Experiments $H_{0}, I$, and $J$ were experiments designed to test the sanitizing effect of microwaves on intentionally contaminated hatching eggs.

In Experiments 1-5, A, F, and $G$ the eggs were irradiated in a multimode chamber designed by the Department of Electrical Engineering and located in the "microwave power laboratory" in the Department of Electrical Engineering. The microwave source was a Phillips Magnetron YJl160 with an AC to DC Staticon Power Supply CT84B5000 R.9 with a variable power output. The chamber was cubical in shape with sides approximately three feet long. The mode stirer was located on the top of the cavity. The eggs to be irradiated were placed, large end up, into a styrofoam egg carton, and the carton placed on a styrofoam pedestal in the center of the floor of the chamber. The power level in watt-seconds of input per egg, in the cavity was calculated by using dummy water loads in evacuated egg shells and measuring the change in temperature of the water due to irradiation. The 
power data calculated by this means for the treatment of 12 eggs at one time is given in Table 1.

In Experiments $B, C, D, E, H$, and $I$ the microwave source was a Raytheon Radarange Model 1162 Unit 7104 with 120/240 V.AC, 3 wire $1 \varnothing 60 \times 49 A$. This machine consists of two 800 watt magnetrons which are located so as to emit irradiations either from the right or left halves of the cavity independently or together to give a higher power. Therefore, for practical purposes the unit has two power levels, 1600 watts or 800 watts. A mode stirer located behind a protective plastic barrier distributes the power output evenly throughout the cavity.

In order to adjust the power absorption of the subject material to the desired levels, and also as a means of calibrating the power absorption, a dummy water load of either 300 or 500 milliliters of water was placed in the left rear corner of the cavity during all experiments.

In Experiments $H$ and $I$ the eggs were placed in a styrofoam egg carton in the center of the oven with a second empty carton serving as a pedestal to lift the eggs closer to the center of the cavity and permit uniform irradiation of the eggs.

In Experiments $B, C, D$, and $E$ the birds were placed in a specially constructed container made of $1 / 2$ inch thick styrofoam approximately $9 " x 6 " x 2 \frac{1}{2} "$ with dividers inside to form 4 separate compartments. This size was found to hold the newly hatched chicks comfortably during 
the experiment. To allow for proper ventilation the box was perforated with $1 / 4$ " diameter holes in the sides, top and bottom. This container was used in all experiments except in Experiment $B$ when it was necessary to observe the actions of the birds. In this case the birds were placed on a styrofoam slab and a clean 300 milliliter beaker was placed over each bird. Ventilation holes were provided in the styrofoam to permit air circulation. After irradiation the birds were placed first in a clean Robbins Incubator hatching tray for observation and to provide air circulation and after partial recovery into a standard chick box.

Incubation and hatching of eggs was carried out when required in a Robbins I-HA incubator located in the Animal Science Building except in Experiment $H$ when eggs were incubated and hatched in a Robbins $11 \mathrm{H}$ incubator located in a separate building.

\section{PRELIMINARY EXPERIMENTS}

Preliminary Experiment 1.

Fifteen groups, with twelve eggs in each were subjected to radiation as show in Table 2. The eggs, from University Shaver Starcross \#288 laying stock, were incubated for one week and then broken out to facilitate examination of the embryos for anomalies. 
Preliminary Experiment 2.

This was an attempt to establish broad limits of maximum tolerance of fertile eggs (embryos) at 0 and 2 days of incubation to various power inputs and times of irradiation as shown in Table 3. Treatment 1 is the stationary control which remained in the incubator throughout the entire period whereas treatments 2 and 3 were fertile eggs at 0 and 2 days of incubation, respectively, which were not subjected to microwave treatment but they travelled from the incubator to the treatment room and back again together with thr treated eggs to determine the effects, if any, of such movement alone and hence are designated as travelling control. Each treatment group consists of 12 fertile eggs of the same stock as in Experiment 1. For treatments 3 to 10 eggs were taken out of the incubator and returned after treatment, whereas all other treatments were applied immediately upon removal of the eggs from refrigeration at $40^{\circ} \mathrm{F}$ after which they were placed into the incubator. All chicks hatched were banded and placed in chick batteries. Hatch weights, weekly weights, and mortality were recorded for three weeks after which the birds were killed and examined for any internal anomalies. Eggs which failed to hatch were broken out and infertility or time of death was estimated. Preliminary Experiment 3.

This experiment was a further attempt to establish the radiation tolerance of fertile eggs and embryos and 
particularly to establish the relationship between time of exposure and rate of power input on such tolerance at specific power inputs. In this case eggs were first allowed to reach room temperature before being irradiated. The treatments are listed in Table 4. All chicks hatched and eggs unhatched were treated as in Experiment 2. Preliminary Experiment 4.

Preliminary Experiment 4 was an extension of the same objective as in Preliminary Experiment 3, which did not yield the desired information, by providing a wider range of power input rate and time of exposure as shown in Table 5. The eggs were allowed to reach room temperature prior to treatment. All chicks hatched and eggs unhatched were treated as in Experiment 2。 Preliminary Experiment 5.

This experiment was essentially the same as Preliminary Experiment 4 except that the exposure and time range was adjusted, as shown in Table 6 , on the basis of information obtained in Preliminary Experiment 4. All chicks hatched and eggs unhatched were treated as in Preliminary Experiment 2。 Experiment A.

Two hundred and forty eggs were divided into two lots of one hundred and twenty eggs each. One group was designated as the control, the other 120 eggs as treatment. Each of these two lots was further subdivided into ten treatment groups of twelve eggs in each to provide 
adequate replication.

The treatments consisted of exposing each of the ten groups to microwave radiation with a power input of 75 watts per egg for a period of fifty-five seconds. This time of exposure was chosen as evidence gained in the preliminary experiment showed that this was the approximate maximum length of irradiation for this power input that would not result in coagulation of egg contents. It was hoped that by excluding visible thermal effects some non-thermal effect would become evident when large numbers of eggs were being treated.

The individual treatment units were distributed randomly throughout the Robbins 1HA incubator. The eggs were candled at five days, to ascertain fertility, and at transfer to remove dead embryos. The incubator was fumigated immediately after the eggs were set with the recommended levels of formalin and potassium permanganate.

All chicks hatched were treated as in Experiment 2 except that the chicks were grown to five weeks of age. Experiment B.

This experiment involved 16 newly hatched Hy-Line type leghorn males. These were divided into four groups of four birds in each treatment. The power output of the Raytheon Radarange on one-half power ( 800 watts) was ascertained by four trials with a dummy water load of $300 \mathrm{mls}$ and no birds, by the following procedure: the pre-irradiation temperature $\left(\mathrm{T}_{1}\right)$ of the $300 \mathrm{mls}$ of 
water was recorded. The water was then irradiated for the desired length of time, nine seconds in this case, and the temperature of the water was then measured after irradiation $\left(\mathrm{T}_{2}\right)$. By using the following formula the power output was calculated.

$$
\text { Watt-seconds }=\frac{\left(\mathrm{T}_{2}-\mathrm{T}_{1}\right) \times \text { Volume of Water }(\mathrm{cc})}{\text { Time }(\text { seconds }) \times .239}
$$

The birds were placed in the microwave chamber in glass beakers as previously described. The temperature of the dumny water load was ascertained and the birds were irradiated for the specified period. After irradiation the temperature of the dummy load was again ascertained and the power absorption calculated.

The difference in watts of power between the power absorbed by the dummy load with and without the presence of the birds in the cavity is assumed to have been absorbed by the birds. As a result the amount of energy absorbed per bird per second can be calculated. By this method the lethal dose of microwave power in this chamber was calculated.

$\begin{aligned} & \text { Energy input/ } \\ & \text { bird/second }\end{aligned}=\frac{\begin{array}{l}\text { Energy absorbed by dummy } \\ \text { load without birds }\end{array}-\begin{array}{l}\text { Energy absorbed } \\ \text { with birds }\end{array}}{4}$ The birds were observed at all times during the irradiation and records kept of their reactions. Immediately after the death of the birds the brains, heart, liver and spleen were removed and placed in formalin. Samples were also taken for comparative purposes from four control birds killed by 
severing their spinal cord at the cranium. The tissues were submitted to the Nanitoba Provincial Veterinary Pathology Laboratory for pathohistological examination as to the cause of death.

Experiment C.

One hundred and sixty-two Hy-Line males were divided into three groups of fifty-four birds. One group was designated as control while the others were designated treatment (a) and (b). Based on observations made in Experiment B it was decided to irradiate treatment (a) for four seconds and treatment (b) for six seconds. The birds were irradiated in the Raytheon Radarange at onehalf power (left tube only) with a dummy load of $300 \mathrm{mls}$ of water included in the chamber. Average energy input per bird was determined as in Experiment B. The birds were irradiated in the styrofoam container previously described. Observations of their activity post-irradiation were recorded. Surviving birds were banded, weighed and grown to three weeks of age after which they were killed and examined for internal abnormalities.

\section{Experiment D.}

One hundred and ten Hy-Line pullets were divided into two equal control and treatment groups. The pullets in the treatment group were irradiated for 4.5 seconds in the Raytheon Radarange at one-half power (left tube only) with a dummy load of $300 \mathrm{mls}$ of water. Energy input per bird was based on previous experiments. The birds were 
irradiated as in Experiment C. Observations were made of the post-irradiation activity of the birds. After a suitable recovery time the pullets were weighed individually and wing banded. The pullets were grown in floor pens with straw litter and incandescent light heating. Mortality and egg production records were kept. All birds that died during the experimental period were examined at the Nanitoba Provincial Veterinary Pathology Laboratory. At 28 weeks of age the birds were mass mated to leghorn type males. Eggs were collected in three consecutive one week periods and incubated to check for possible genetic effects of microwave treatment. All chicks from these matings were examined for abnormalities. Those eggs which failed to hatch were broken out and infertility or stage of embryonic development and cause of death were estimated. Experiment E.

Approximately 450 female chicks of three strains, namely, Shaver Starcross, Hy-Line and Babcock B300 were obtained from commercial hatcheries. Each strain was divided into two equal groups of 225 chicks, one was the control group and the other was subject to the same treatment as in Experiment D. Treated and control females of the same strain were grown intermingled but strains were separated to allow measurements of strain differences in treatment response.

The chicks were wing banded and mortality recorded to 20 weeks of age. All birds dying of unknown causes 
were sent to the Nanitoba Provincial Veterinary Pathology Laboratory for autopsy. Age at date of first egg production was recorded for each strain. Experiments $F$ and $G$.

As these two experiments are very similar they will be described together. In Experiment F, 24 dozen eggs, and in Experiment G 26 dozen eggs, were used. The eggs were from the University of Manitoba egg laying stock. The eggs were divided into two equal groups, control and treated. In each experiment there were equal number of subgroups designated "warm", or "cold". The "cold" eggs were kept in a cooler at approximately $+40^{\circ} \mathrm{F}$ while the "warm" eggs were stored at room temperature on a shelf in the Animal Science physiology laboratory. The "treatment" eggs were exposed to 75 watts of power input per egg for 65 seconds. After the exposure the eggs were placed into storage with an equal number of non-irradiated control eggs.

At regular intervals eggs were removed from storage and the interior quality of the eggs measured by the Haugh unit system. The "warm" eggs were measured more frequently than the cooler eggs because it is an accepted fact that interior quality deteriorates faster at high temperatures than cold temperatures and hence a better estimate of treatment effect on quality could be made with more frequent analysis of the "warm" eggs. The eggs were analysed on the days as listed in Tables 40 and 41. 
Experiments $\mathrm{H}_{0} \mathrm{I}$ and $\mathrm{J}_{0}$

As these three experiments are similar in design they will be discussed together.

In Experiment $\mathrm{H}, 310$ eggs from the Shaver Starcross stock mating were divided into four groups designated as follows 8 Group M, 100 eggs; Group 0, 100 eggs; Group Cl, 55 eggs; Group C2, 55 eggs. One week prior to irradiation and setting, Groups $M$ and 0 were dipped into a warm water solution of chicken feces, collected from litter under laying hen cages, to produce contaminated eggs. Swabs of eggs dipped in this manner were tested by the Provincial Veterinary Laboratory which showed that the dipped eggs had significantly more bacteria on the surface than non-dipped eggs. This confirmed that the eggs were indeed "contaminated".

On the morning prior to setting, the eggs of Group $M$ were subjected to an exposure of 35 seconds duration of microwave power with an input of 75 watts per egg. The eggs were then placed in an incubator so that the clean eggs were near a fresh air inlet, whereas the contaminated eggs were near the air exhaust. This was done so as to minimize contamination of the control eggs by airborn bacteria from groups $M$ or 0 .

All chicks hatched were examined for abnormalities. Those eggs which did not hatch were broken out and infertility or the time and cause of death were ascertained. 
In Experiments $I$ and $J_{0} 270$ eggs collected from the Hy-Line mating from the University of Manitoba laying: flock were used in three groups of 90 eggs, Group M, Group 0, and Group C. These groups were treated in a similar manner to those in Experiment $H$ except that in Experiment $H$ the eggs were incubated in the Robbins $11 \mathrm{H}$ incubator while in Experiments $I$ and $J$ the Robbins I-HA incubator was used. 
Preliminary Experiment 1.

From the results in Table 2 it can be seen that the range of microwave treatments applied at 0,1 or 2 days of incubation had no effect on survival of embryos to one week of development.

In view of this, subsequent tests involved a wider range of time/power input treatments to determine tolerance limits of irradiation. Furthermore in subsequent tests, eggs were incubated to hatching and chicks were grown to three weeks of age to determine the effect, if any, on hatchability, and on early growth and livability of the chicks. Preliminary Experiment 2.

The hatchabilities of the experimental treatments as well as the eggs which showed coagulation of protein due to thermal effects of microwaves are listed in Table 3.

Since hatchability for each egg (embryo) is an all or none response which is indicated by a single statistic (percent hatchability) for each group of eggs, the test conducted did not permit statistical analysis of the results since there was only one group per treatment. However results show that exposure of eggs, after two days of incubation, to 75 watts/egg input for 45 seconds reduced hatchability to $33 \%$. of the eight 
dead embryos (67\%) seven died within two days of treatment whereas one survived to the 18 th day of development, but all eight eggs showed coagulation of egg contents. Exposure to 60 or 90 seconds at 75 watts/egg was lethal to all embryos within two days of treatment and all such eggs showed coagulation of egg contents. Usually both the albumen and the yolk were coagulated in the same area of the egg which did not include the embryo. Hence the heat level at the blastodisc did not reach a visible coagulation point, but it is possible that some biochemical changes were induced that prevented further development of the embryo.

It is evident from Table 3 when the power input was lowered to 34 watts/egg, approximately one-half the earlier level, the time required to induce the same effect was approximately doubled, i.e. at 90 seconds of irradiation with 34 watts/egg input the effect is very similar to that achieved with an exposure of 45 seconds at 75 watts/egg. At 120 second and 160 second treatment with 34 watts/egg the effect was similar to that from 60 and 90 second exposures at 75 watts/egg as all embryos were killed.

It was also observed that fresh fertile eggs, irradiated directly after removal from the cooler. (treatments 11 to 14, Table 9), were not heated to a high enough temperature during the treatment period to cause coagulation of the egg constituents and their hatchability was quite normal. Hence it was decided that in further 
studies any eggs to be treated prior to incubation would be warmed to room temperature prior to irradiation. Preliminary Experiment 3.

The hatchability results of Preliminary Experiment 3 are given in Table 4. It can be seen that the hatchability of the pre-incubation treated eggs in this trial was relatively normal. Increasing the exposure from 35 to 60 seconds at 75 watts/egg power input resulted in a definite drop in hatchability to 0 accompanied by an increase in the number of coagulated eggs.

As in Experiment 2 it was found that when the energy input was cut by one-half the time required to get a similar response was approximately doubled. This study established tolerance limits for the eggs irradiated at two days incubation.

Preliminary Experiments 4 and 5.

Results of these two experiments (Tables 5 and 6 ) which involve treatment of fresh fertile eggs, clearly indicate that such eggs, which in fact are embryos at about 20 hours of development, have a greater tolerance to radiation than embryos at two days incubation, as even the higher doses of irradiation were not lethal $100 \%$ of the time.

It was reported by Romanoff (1967) that the process of incubation results in several biochemical changes within the egg. These changes involve carbohydrates, protein, lipids and water. Accompanying these changes will be an 
alteration of the specific heat and the heating pattern of the egg with regards to thermal microwave interactions. The biochemical changes also result in an alteration of the susceptability of various egg components to applied heat.

It is these phenomena that result in variation in the net effect of different doses of microwave power especially at two days of incubation.

There was a trend, as in previous experiments, indicating that the total radiation dose was the critical factor rather than the rate of input or time of irradiation exposure. The incidence of death because of coagulation of egg constituents was higher in those eggs receiving the maximum total radiation dosage input.

There is no relationship between hatchability of chicks in any treatment and their body weight.

In Preliminary Experiments 2 through 5 (Tables 3, 4, 5, and 6) no differences were found in total weight gain between any of the treatments and the control, or between any two treatments (Tables $7,8,9$, and 10).

In the fifth preliminary study a one way analysis showed a significant treatment effect on body weight at three weeks $(P<.05)$ (Table 10). Duncan's test of the data revealed that birds in treatment number 9, which was for 210 seconds at 34 watts input, were significantly lighter than the birds in the other 12 groups. This group contained the most coagulated eggs which may have 
been due to an experimental error which resulted in a radiation overdose. Other groups receiving radiation doses showed no significant effect on body weight. Experiment A.

The percent hatchabilities and average hatch weight of the various treatment groups in this experiment are given in Table 11 .

Analysis of variance, after transformation of values to arcsin, revealed no significant difference in hatchability between control and treatment groups (Table 12). Control hatchability varied between $66.6 \%$ and $91.6 \%$ whereas treatment hatchabilities varied from 50 to 100\%. Eight of the eggs which failed to hatch, on close examination, showed some level of coagulation of either yolk or albumen. Two of these eggs contained embryos which had developed to approximately 19 days of age before dying whereas mortality in others occurred within two days of treatment. Death could presumably have occurred because of the inability of the chick to absorb the coagulated portion of the yolk, thus resulting in inadequate supplies of nutrients. There were no malformations in either the chicks hatched or in the dead embryos.

Analysis of variance of hatching weights showed no significant differences because of treatment (Table 13). Also analysis of variance of body weights and weight gains to four weeks showed no significant difference because of treatment (Tables 14, 15, 16, 17, 18, and 19). 
Mortality data presented in Table 20 showed no consistent cause of death among the nine birds dying during the course of the experiment and none of the deaths could be attributed to the irradiation of the blastodisc prior to incubation.

At this time a question was raised as to the validity of the energy input measurement used to calibrate the microwave oven. It was suggested that initial energy input calibrations executed by substitution of water for actual egg contents could differ from those based on normal fresh eggs.

As a check, temperature increases on eggs were measured by inserting a thermo-couple into the center of an egg immediately following irradiation for various times, eg. 20, 30, 40 up to 100 seconds. The temperatures were plotted on a graph and a line representing the timetemperature relationship was constructed. These tests were run on the 75 watts level and on the 34 watts input level. These curves are illustrated in Figures 1 and 2. By selecting a time period of 60 seconds and utilizing eggs which were calculated to have a volume of $58 \mathrm{cc}$ and a specific heat of 9 , calculations of energy input per egg were made. These calculations revealed that the actual power inputs for the former 75 watt and 34 watt calibrations were 80.08 watts and 36.40 watts respectively. This represents an error of $6.8 \%$ and $7 \%$, respectively. 
It was felt that these errors were within the acceptable range of experimental tolerance because of the variability between eggs in size and shape which would affect the pattern of radiation waves in the chamber and hence the power.

Experiment B。

Irradiation of groups of birds for periods of 7,8, or 9 seconds with an energy output of 800 watts-second revealed that there were no visible movements of the chicks after a nine second irradiation period. It was concluded that death occurred immediately with a nine second irradiation period, and hence this time/power treatment was the basis of calculating the lethal power absorption level per bird.

Calculations based on water temperature changes within the chamber (as explained previously) revealed that each bird was exposed to a level of 88.66 watts exposure input or a total energy input of 797.96 watts-sec. Therefore approximately 800 watts-sec. of energy input/ bird is considered as the lethal dose. Histological examination of the tissues from the birds killed during microwave irradiation revealed the following: "Occasional large neurons in the basal ganglia of the midbrain are very basophilic. There was clumping and margination of Nissl substance, with lysis of nuclear chromatin. These changes were also found in control birds and are considered to be normal neuronal attrition. Fine 
fatty vacuolation of hepatocytes were considered normal in young chicks. Primary diagnosis: no light microscopic changes, samples normal"。

It is not known whether death is due to a direct thermal effect or to resulting biochemical changes. Milroy and Michaelson (1971) suggest death is due to acidosis, hyperpnea, lacrimation and tetany leading to respiratory arrest. Experiment $C_{0}$

Total energy input was estimated for the four and six second treatments at 392.0 watt-sec and 596 watt-sec per bird respectively. This is $49 \%$ and $74.5 \%$ of the previously established lethal dose.

During the irradiation period the birds showed extreme muscular contractions and violent body movements. The head was drawn backwards, rapid movement of the limbs resulted and in most cases the birds turned themselves onto their backs. Loud vocalizations were produced for the first two to three seconds but ceased after the birds become turned over. In the four second exposure the birds remained conscious, but in the six second exposure consciousness appeared to be lost after approximately five seconds. This substantiates the work of Tanner (1969)。

The recovery phase in both situations was noteworthy. After four seconds of irradiation the birds showed extreme hyperactivity accompanied by loud vocalization for 
up to five minutes. After this hyperactive period the birds became quiet and a stage of somnolence set in. They sat with wings extended and hyperventilated for up to 15 minutes.

After six seconds of irradiation the birds were unconscious, a state which lasted from .5 to 5 minutes. Death of some birds resulting from the irradiation stress occurred within this period. Those birds which regained consciousness then passed through a state of excitation and hyperactivity similar to that of the birds treated for only four seconds. Chirping, flapping of wings and rapid movements which include jumping were common. This active period was followed by a period of somnolence during which the birds sat with wings extended and hyperventilated until a more normal body temperature was regained. These birds showed marked discoloration of small areas of the legs and beak which appeared to be burns to the skin and underlying tissue. These burns were possibly caused by the inability of the chick to dissipate heat produced in these areas due to the relatively low level of vascularization of this tissue. Burns caused by microwave irradiation have been reported by Milroy and Michaelson (1971). Approximately two hours after treatment the control and four second treatment birds were much more active than their six second counterparts. After recovery the six second irradiated group demonstrated a tendency to sit or stand with the head lower than the normal position. 
As it was planned that there be 52 birds grown in each group, more birds were required to be irradiated to allow for birds dying during treatment since $42 \%$ of the birds died immediately following treatment with six seconds of exposure. However, unlike those birds dying in the lethal dose experiment, these birds survived the treatment period and died after being removed from the chamber.

It was necessary to ascertain if there was any size difference between the surviving and dead birds that could have caused certain birds to die while others lived. The surviving birds had a mean weight of $35.42 \mathrm{~g}$ while the dead birds had a mean of $36.50 \mathrm{~g}$. Analysis of variance of the weights of the dead and live birds showed no significant difference. It may be assumed that size did not affect survival (Table 2l).

Analysis of variance of the initial weights of groups A, B and Control (Table 22) showed that there was a significant $(P<0.01)$ chance difference in the weights of the three groups. Further analysis by Duncan ${ }^{\circ} \mathrm{s}$ test showed the Control group significantly lighter $(P<0.01)$ than either groups A or B while groups A and B were not different.

Analysis of variance of the actual weights and weight gains to one week of age (Tables 23, 24, and 25) revealed a highly significant $(P<0.01)$ difference between the three groups. Further analysis with a Duncan's test revealed that for the actual weights at one week treatment 
$B$ was significantly different from the Control $(P<0.01)$ and from treatment $A(P<0.05)$ whereas treatment $A$ and Control were not different. The weight gain data for the period showed treatment $B$ significantly different from the Control $(P<0.01)$ and from treatment $A(P<0.05)$. Also treatment A was significantly different from that of Control ( $P<0.01)$. Reference to the data (Table 23) reveals that treatment $B$, the six second group, had the least growth followed by treatment $A$, the four second group. Also actual weights at one week of age show that the controls had caught up to the A group that was significantly larger one week earlier.

The reduced growth rates exhibited by groups A and B may have been because of nutrient utilization for repair of radiation damaged leg tissues, as there was no evidence of internal histological change and normal growth coincides with full recovery from this superficial damage. Analysis of variance of weights and gains at two weeks of age showed a highly significant $(P<0.01)$ difference (Tables 26 and 27). The level of significance of the difference between groups is less during the second week of growth (Table 28) because of the recovery and improved rate of growth during this period.

Duncan's test revealed that for actual bird weights at two weeks group B was significantly lighter than either group $A_{0}(P<0.05)$ or the Control $(P<0.01)$. Duncan ${ }^{\circ} s$ test showed that the difference in gains between group A 
and the Control was significant at the $5 \%$ level whereas between group $B$ and the Control it was at the $1 \%$ level. Group B (six second treated birds) gained significantly less weight than group A (four second treated birds) $(P<0.05)$.

Duncan's test of the weight gained in the second week of growth showed that group $B$ gained significantly less weight than the controls $(P<0.01)$ or group $A(P<0.05)$, whereas group A was similar to the controls.

Examination of the birds at this time showed that the burns to the leg regions were still quite evident. In some cases blistering and seepage of sera was evident while other chicks showed atrophy of the leg below the burn. A few chicks showed increased growth of the tissue immediately above the burn. All surviving group B birds showed at least a slight amount of damage noted by leg discoloration or one of the previously mentioned more severe lesions. No lesions were seen on group A birds. The overall weight gains suggest that both groups $A$ and $B$ were severely set back by the microwave treatment. However, the weight gain data for the last week show that group $A$ and the control were gaining at an equal rate which suggests that damage caused by the treatment of group A had been repaired. Group B had not fully recovered from burns and therefore did not grow at a greater rate.

Analysis of the actual weights at three weeks 
(Table 29) showed the treatments significantly different at the $5 \%$ level. On the basis of Duncan's test group B was significantly different from the control ( $P<0.05)$, but it was not different from group A which was not different from the control.

Analysis of the three week weight gains (Table 30) showed that group $B$ gained significantly less $(P<0.01)$ than the controls but was not different from group A which was not different from the control.

Analysis of variance of the weight gains in the last week of growth (Table 31) showed that all groups were gaining at similar rates. Examination revealed that birds previously showing physical damage were now visibly "normal" except for two birds which lost the lower portion of one leg. This suggests that at this stage the birds showed no ill effects from microwave radiation. Mortality was low during the growth period with only six deaths recorded, three in group B, two in control and one in group A. All but one bird died from gizzard impaction as a result of ingesting straw. The sixth bird (treated for four seconds) died from starvation.

It was decided to repeat the experiment with 4.5 seconds exposure on newly hatched pullets and grow them to maturity and reproduction. It was felt that chromosomal abberations in ovogeneses, may be evident in the progeny. 


\section{Experiment D.}

As in the previous experiments a definite pattern of behavior followed irradiation of the young pullets. After removal from the styrofoam irradiation container all birds showed some level of respiratory distress. The visible dermal areas such as beak and legs were very red in color due to increased vascular circulation. The birds remained inactive for five to fifteen seconds post-irradiation and then approximately $90 \%$ of the birds passed through a stage of extreme excitation. This stage was marked by a sudden increase in motor activity, running, jumping and flapping of wings. This period lasted from five to ten seconds. Following this stage the wings were spread and hyperventilation continued until a normal temperature had been reestablished. Only one death occurred as a result of treatment. Post-mortem examination failed to reveal any visible cause of death.

During the period from treatment to 40 weeks of age mortality data (Table 32) shows that two birds died in the control group, one at three days of age from gizzard impaction and the other at 32 weeks of age with no visible lesions. However in the control group in the same period 19 birds died. Of these, 13 birds or $68 \%$ of the deaths were diagnosed as Mareks disease. The other six birds died from other common problems such as peritonitis, gizzard impaction or emaciation. It appeared that the treating of newly hatched pullets could possibly play a 
part in the prevention of Mareks disease.

At the end of a 100 day laying period from August 1 . 1973 to November 8, 1973 compilation of the hen day production revealed that both groups were equal in average production (Table 33) but peak production was $85.0 \%$ for treated birds and $91.0 \%$ for control birds.

In approximately the middle of the 100 day laying test three consecutive hatchability studies were conducted. The results of the first setting were discarded due to an incubator failure. In the subsequent two tests no difference in hatchability of eggs from the control and treated groups was observed (Table 34). Fertility was similar for the two groups in the two tests, $89.5 \%$ in the controls and $90.5 \%$ in the treated group. Experiment E。

As in Experiments $C$ and $D$ the pullets went through a definite pattern of activity post irradiation. The familiar excitation phase followed by a period of somnolence in which the birds probably readjust their temperature occursed with little or no deviation from the pattern of activity described in previous experiments.

The apparent severity of the treatment seemed to differ between the three strains of birds. The Hy-Iine pullets were most severely affected by the treatment and took by far the longest period of time to regain normal function. The Shaver pullets were affected to a lesser degree while the Babcock pullets showed a rapid recovery. 
The leg injuries noted in the previous experiment were also observed during this trial. Burns were confined to the Shaver and Hy-Line pullets with none being apparent on the Babcock stock.

The Babcock birds were noted to be generally more active than the other strains both before and after irradiation. This observed difference in behavior between the three strains may be due to their genetic differences or to differences in pre-treatment environment of the three groups.

Nortality data collected on the pullets during the growing period is divided into two sections, 0 to 4 weeks and 5 weeks to 20 weeks (Tables 35, 36 and 37).

Due to a difference of one week in hatching date between one group of chicks and the other two groups used in the tests, and because of some environmental differences in the brooder house during this period which may have affected livability, it was considered advisable not to attach any importance to mortality occurring during the first four weeks. This four week period would also allow time for recovery of the birds from superficial burns induced by treatment.

Mortality data for the period from 5 to 20 weeks of age is presented in Tables 35, 36, and 37. Nortality in this period was lowest in the Shaver stock while the HyLine and Babcock stock were considerably higher. Statistical analysis of the mortality due to Mareks Disease and 
analysis of the overall mortality (Tables 38 and 39) revealed neither treatment nor strain effect. The majority of deaths in all groups was caused by Mareks Disease. Experiments $F$ and $G$.

The mean Haugh unit values for control and treated groups for each day of measurement are given in Tables 40 and 4I. Analysis of the Haugh unit values ascertained from the eggs stored either at room temperature or at $40^{\circ} \mathrm{F}$ in a large cooler after irradiation, showed no consistently significant difference (Tables 42, 43, 44, and 45) in internal quality between eggs treated with microwaves or control eggs stored for equal periods. On two days in Experiment $F$ and one day in Experiment $G$ significant differences were found between the control and treated eggs $(P<0.05)$. In two of the three cases of significance the treated eggs were better than the control. These differences were transitory and were not found in the succeeding set of measurements taken at the next later date. over a long period of time ( 42 days) the control and treated eggs were essentially of the same quality.

The reason for the significance between treatments on three days out of 24 is most likely due to chance. It is possible that on day 0 the albumen of the treated eggs was "firmed" up by the heat resulting from irradiation. Cook books often recommend "freshening" eggs by dipping them in hot water for 5 to 10 seconds before opening. 
There is no scientific basis for this recommendation, however, the microwave treatment might have the same effect as the water in that the albumen is thickened slightly on warming.

Experiments $\mathrm{H}_{2} \mathrm{I}_{2}$ and $\mathrm{J}$.

Hatchabilities of treatments in Experiments $\mathrm{H}, \mathrm{I}$, and $J$ are given in Table 46. In Experiment $H$ there was a marked difference between the treated and untreated eggs. This difference was not evident in either Experiment I or J。

The superior hatchability of the microwave treated contaminated eggs of Experiment $H$ suggests that microwave radiation is beneficial with regards to sanitization of eggs, however, the absence of similar effects in Experiments $I$ and $J$ contradicts this suggestion. All chicks hatched were normal. 


\section{CONCLUSIONS}

The level of microwave radiation required to constitute a lethal dose to the developing chicken embryo is governed by the stage of embryo development. At 2 days of incubation 75 watts of power input for more than 45 seconds of exposure will result in death to all embryos, while pre-incubation treatment with 75 watts power input for up to 80 seconds results in only $25 \%$ mortality. Death is the result of thermal coagulation of either the albumen or yolk, or sometimes both, therefore preventing normal assimilation of nutrients. Microwave irradiated embryos which hatched showed no effects due to irradiation to four weeks of growth. Microwave radiation of chicken embryos, below levels that cause visible thermal alteration of egg constituents had no adverse effects on the embryos or the growth of the chick to four weeks of age.

A dose of 800 watts-sec total energy input was found to be lethal to a day old chick. No histological changes were found in the tissues of chicks which died from microwave irradiation. Exposure to sublethal levels of microwave power input resulted in burns to leg tissues, however no long term effects on growth, mortality or production were evident.

On the basis of treatments tested the lethal dose for a chick appears to be 800 watts-sec absorbed over 9 seconds. Accepting the information of Bell and Freeman 
(1971) that the surface area of a day old chick is $85 \mathrm{~cm}^{2}$, the lethal density calculates to $800 \div 9$ sec $\div 85=1.043$ w/ $\mathrm{cm}^{2}$ for 9 seconds. This density applied for 4 seconds showed no harmful effect, but allowing a safety margin and assuming that the safe dose is $1 / 1000$ of the lethal dose, this would set the safe dose for chicks at $1 \mathrm{mw} / \mathrm{cm}^{2}$ for 9 seconds. This is comparable to the safe dose for humans of $10 \mathrm{mw} / \mathrm{cm}^{2}$ for 6 seconds (CSA Standard 265-1966) which has now been reduced to $1 \mathrm{mw} / \mathrm{cm}^{2}$ for 6 seconds. Exposure of fresh infertile eggs to a power input of 75 watts for 65 seconds had no effects on the keeping quality of eggs stored either with or without refrigeration for up to 42 days.

Exposure of fresh, fertile bacterially contaminated eggs to 75 watts power input for 35 seconds had no effect on sanitization of the eggs.

In summary, exposure to microwave irradiation at levels below those that result in thermal damage has no effect on the quality of fresh eggs, development of embryos or performance of surviving birds. 
Table 1. Power input and radiation density data for multimode chamber with a load of one dozen eggs

\begin{tabular}{ccc}
\hline $\begin{array}{c}\text { Power source } \\
\mathrm{ma}^{*}\end{array}$ & $\begin{array}{c}\text { Power input per egg } \\
\text { in watts }\end{array}$ & $\begin{array}{c}\text { Density } \\
\mathrm{w} / \mathrm{cm}^{2}\end{array}$ \\
\cline { 2 - 3 } 430 & 75 & 1.3 \\
220 & 34 & .585 \\
165 & 27.2 & .470 \\
138 & 18.0 & .316 \\
124 & 15.1 & .260 \\
110 & 6.6 & .115 \\
50 & 1.77 & .033 \\
\hline
\end{tabular}

* milliamps 
Table 2. Preliminary Experiment 1: Treatments and percent normal embryos at one week incubation.

\begin{tabular}{|c|c|c|c|c|}
\hline $\begin{array}{l}\text { Treatment } \\
\text { number }\end{array}$ & $\begin{array}{c}\text { Power input } \\
\text { per egg } \\
\text { in watts } \\
\end{array}$ & $\begin{array}{l}\text { Length of exposure } \\
\text { (seconds) }\end{array}$ & $\begin{array}{c}\text { Day of } \\
\text { incubation } \\
\text { at irradiation }\end{array}$ & $\begin{array}{l}\% \text { Normal } \\
\text { embryos } \\
\text { at } 1 \text { week }\end{array}$ \\
\hline 1 & 0 & Stationary Control & & 75.0 \\
\hline 2 & 0 & Travelling Control & 0 & 100.0 \\
\hline 3 & 0 & Travelling Control & 1 & 100.0 \\
\hline 4 & 0 & Travelling Control & 2 & 100.0 \\
\hline 5 & 75 & 30 & 1 & 100.0 \\
\hline 6 & 75 & 30 & 2 & 91.6 \\
\hline$?$ & 75 & 20 & 2 & 100.0 \\
\hline 8 & 75 & 45 & 2 & 100.0 \\
\hline 9 & 75 & 45 & 0 & 100.0 \\
\hline 10 & 15.1 & 120 & 1 & 91.6 \\
\hline 11 & 15.1 & 120 & 2 & 100.0 \\
\hline 12 & 15.1 & 90 & 2 & 91.6 \\
\hline 13 & 15.1 & 150 & 2 & 100.0 \\
\hline 14 & 6.6 & 150 & 2 & 100.0 \\
\hline 15 & 6.6 & 180 & 2 & 100.0 \\
\hline
\end{tabular}


Table 3. Preliminary Experiment 28 Treatments, percent hatchability, number of coagulated eggs, and mean three week weight gain.

\begin{tabular}{|c|c|c|c|c|c|c|}
\hline $\begin{array}{l}\text { Treatment } \\
\text { number } \\
\end{array}$ & $\begin{array}{l}\text { Power input } \\
\text { per egg } \\
\text { in watts } \\
\end{array}$ & $\begin{array}{l}\text { Length of exposure } \\
\text { (seconds) }\end{array}$ & $\begin{array}{l}\text { Day of in- } \\
\text { cubation at } \\
\text { irradiation }\end{array}$ & $\begin{array}{l}\text { Percent } \\
\text { hatch- } \\
\text { ability }\end{array}$ & $\begin{array}{c}\text { Number } \\
\text { coagulated }\end{array}$ & $\begin{array}{l}\text { Mean } \\
3 \text { week } \\
\text { weight } \\
\text { gain }\end{array}$ \\
\hline 1 & 0 & Stationary Control & & 91.6 & & 139.90 \\
\hline 2 & 0 & Travelling Control & 0 & 100.0 & & 138.64 \\
\hline 3 & 0 & Travelling Control & 2 & 100.0 & & 145.0 \\
\hline 4 & 75 & 30 & 2 & 75.0 & 1 & 147.0 \\
\hline 5 & 75 & 45 & 2 & 33.0 & 8 & 163.0 \\
\hline 6 & 75 & 60 & 2 & 0.0 & 12 & \\
\hline 7 & 75 & 90 & 2 & 0.0 & 12 & \\
\hline 8 & 34 & 90 & 2 & 58.3 & 4 & 135.57 \\
\hline 9 & 34 & 120 & 2 & 0.0 & 12 & \\
\hline 10 & 34 & 160 & 2 & 0.0 & 12 & \\
\hline 11 & 75 & 45 & 0 & 100.0 & & 135.92 \\
\hline 12 & 75 & 60 & 0 & 66.6 & & 147.43 \\
\hline 13 & 75 & 75 & 0 & 75.0 & & 150.11 \\
\hline 14 & 75 & 90 & 0 & 100.0 & & 137.82 \\
\hline
\end{tabular}


Table 4. Preliminary Experiment 3: Treatments, percent

hatchability, number of coagulated eggs, and mean three week weight gain.

\begin{tabular}{|c|c|c|c|c|c|c|}
\hline $\begin{array}{l}\text { Treatment } \\
\text { number }\end{array}$ & $\begin{array}{l}\text { Power input } \\
\text { per egg } \\
\text { in watts } \\
\end{array}$ & $\begin{array}{l}\text { Length of exposure } \\
\text { (seconds) }\end{array}$ & $\begin{array}{l}\text { Day of in- } \\
\text { cubation at } \\
\text { irradiation }\end{array}$ & $\begin{array}{l}\text { Percent } \\
\text { hatch- } \\
\text { ability }\end{array}$ & $\begin{array}{c}\text { Number } \\
\text { coagulated }\end{array}$ & $\begin{array}{l}\text { Mean } \\
3 \text { week } \\
\text { weight } \\
\text { gain }\end{array}$ \\
\hline 1 & 75 & 20 & 0 & 75.0 & & 136.22 \\
\hline 2 & 75 & 30 & 0 & 91.6 & & 133.20 \\
\hline 3 & 75 & 40 & 0 & 100.0 & & 159.45 \\
\hline 4 & 75 & 50 & 0 & 91.6 & & 139.27 \\
\hline 5 & 75 & 30 & 2 & 50.0 & & 145.83 \\
\hline 6 & 75 & 35 & 2 & 90.9 & & 155.90 \\
\hline 7 & 75 & 40 & 2 & 77.7 & 3 & 152.33 \\
\hline 8 & 75 & 45 & 2 & 33.3 & 4 & 149.25 \\
\hline 9 & 75 & 50 & 2 & 25.0 & 5 & 117.66 \\
\hline 10 & 75 & 55 & 2 & 8.3 & 9 & 146.0 \\
\hline 11 & 75 & 60 & 2 & 0.0 & 12 & \\
\hline 12 & 34 & 75 & 2 & 83.3 & & 149.11 \\
\hline 13 & 34 & 90 & 2 & 41.6 & 3 & 151.75 \\
\hline 14 & 34 & 105 & 2 & 8.3 & 9 & 165.0 \\
\hline 15 & 0 & Stationary Control & & 91.6 & & 140.0 \\
\hline 16 & 0 & Travelling Control & 2 & 90.9 & & 133.80 \\
\hline
\end{tabular}


Table 5. Preliminary Experiment 48 Treatments, percent hatchability, and three week weight gain.

\begin{tabular}{|c|c|c|c|c|c|}
\hline $\begin{array}{l}\text { Treatment } \\
\text { number }\end{array}$ & $\begin{array}{c}\text { Power input } \\
\text { per egg } \\
\text { in watts } \\
\end{array}$ & $\begin{array}{l}\text { Length of exposure } \\
\text { (seconds) }\end{array}$ & $\begin{array}{l}\text { Day of in- } \\
\text { cubation at } \\
\text { irradiation }\end{array}$ & $\begin{array}{c}\text { Percent } \\
\text { hatchability }\end{array}$ & $\begin{array}{l}\text { Mean } 3 \text { week } \\
\text { weight gain }\end{array}$ \\
\hline 1 & 0 & Stationary Control & 0 & 83.3 & $146.0 \mathrm{~g}$ \\
\hline 2 & 0 & Travelling Control & 0 & 100.0 & 138.36 \\
\hline 3 & 75 & 40 & 0 & 75.0 & 148.77 \\
\hline 4 & 75 & 50 & 0 & 100.0 & 145.63 \\
\hline 5 & 75 & 60 & 0 & 75.0 & 151.44 \\
\hline 6 & 75 & 70 & 0 & 91.6 & 141.81 \\
\hline 7 & 34 & 90 & 0 & 83.3 & 138.0 \\
\hline 8 & 34 & 120 & 0 & 91.6 & 148.09 \\
\hline 9 & 34 & 150 & 0 & 100.0 & 139.3 \\
\hline 10 & 18 & 160 & 0 & 83.3 & 165.57 \\
\hline 11 & 18 & 200 & 0 & 83.3 & 133.77 \\
\hline 12 & 18 & 250 & 0 & 75.0 & 150.66 \\
\hline 13 & 18 & 300 & 0 & 66.0 & 137.62 \\
\hline
\end{tabular}


Table 6. Preliminary Experiment 58 Treatments, percent hatchability, number of coagulated eggs, and mean three week weight gain.

\begin{tabular}{|c|c|c|c|c|c|c|}
\hline $\begin{array}{l}\text { Treatment } \\
\text { number }\end{array}$ & $\begin{array}{l}\text { Power input } \\
\text { per egg } \\
\text { in watts } \\
\end{array}$ & $\begin{array}{c}\text { Length of exposure } \\
\text { (seconds) }\end{array}$ & $\begin{array}{l}\text { Day of in- } \\
\text { cubation at } \\
\text { irradiation }\end{array}$ & $\begin{array}{l}\text { Percent } \\
\text { hatch- } \\
\text { ability }\end{array}$ & $\begin{array}{c}\text { Number } \\
\text { coagulated }\end{array}$ & $\begin{array}{l}\text { Mean } \\
3 \text { week } \\
\text { weight } \\
\text { gain } \\
\end{array}$ \\
\hline 1 & 0 & Stationary Control & & 100.0 & & 126.42 \\
\hline 2 & 0 & Travelling Control & 0 & 91.6 & & 122.27 \\
\hline 3 & 75 & 60 & 0 & 91.6 & & 140.18 \\
\hline 4 & 75 & 70 & 0 & 100.0 & & 143.25 \\
\hline 5 & 75 & 80 & 0 & 75.0 & 1 & 145.67 \\
\hline 6 & 34 & 90 & 0 & 75.0 & & 143.50 \\
\hline 7 & 34 & 150 & 0 & 83.3 & 1 & 131.10 \\
\hline 8 & 34 & 180 & 0 & 58.3 & 3 & 130.67 \\
\hline 9 & 34 & 210 & 0 & 33.3 & 7 & 99.00 \\
\hline 10 & 18 & 210 & 0 & 58.3 & & 139.71 \\
\hline 11 & 18 & 250 & 0 & 75.0 & & 143.44 \\
\hline 12 & 18 & 300 & 0 & 75.0 & & 141.78 \\
\hline 13 & 18 & 350 & 0 & 50.0 & 5 & 127.40 \\
\hline
\end{tabular}


Table 7. Preliminary Experiment 2: Analysis of variance of the mean three week weight gain by treatments.

$\begin{array}{lrcc}\text { Source } & d f & \text { MS } & f \\ \text { Treatments } & 9 & 438.30 & 1.148 \\ \text { Error } & 82 & 381.54 & \\ \text { Total } & 91 & & \end{array}$

Table 8. Preliminary Experiment 3: Analysis of variance of the mean three week weight gain by treatments.

$\begin{array}{lccc}\text { Source } & \text { df } & \text { NS } & \text { f } \\ \text { Treatments } & 14 & 767.45 & 1.280 \\ \text { Error } & 90 & 595.37 & \\ \text { Total } & 104 & & \end{array}$


Table 9. Preliminary Experiment 4: Analysis of variance of the mean three week weight gain by treatments.

\begin{tabular}{lrcc}
\hline Source & df & MS & f \\
Treatments & 12 & 560.60 & 1.14 \\
Error & 110 & 490.82 & \\
Total & 122 & &
\end{tabular}

Table 10. Preliminary Experiment 5: Analysis of variance of the mean three week weight gain by treatments.

$\begin{array}{lrrc}\text { Source } & \text { df } & \text { MS } & \text { f } \\ \text { Treatments } & 12 & 1027.36 & 2.21 \% \\ \text { Error } & 100 & 464.38 & \\ \text { Total } & 112 & & \end{array}$


Table 11. Experiment A: Percent hatchability and mean body weight at hatching of chicks.

\begin{tabular}{|c|c|c|c|c|}
\hline Group & Control & $\begin{array}{c}\text { Hatching } \\
\text { body } \\
\text { weight } \\
\end{array}$ & Treatment & $\begin{array}{c}\text { Hatching } \\
\text { body } \\
\text { weight } \\
\end{array}$ \\
\hline 1 & $75.0 \%$ & 39.30 & $83.3 \%$ & 36.50 \\
\hline 2 & 83.3 & 38.00 & 83.3 & 39.10 \\
\hline 3 & 66.6 & 38.50 & 75.0 & 39.00 \\
\hline 4 & 83.3 & 38.00 & 100.0 & 40.20 \\
\hline 5 & 83.3 & 38.70 & 50.0 & 39.80 \\
\hline 6 & 83.3 & 39.30 & 83.3 & 38.70 \\
\hline 7 & 91.6 & 38.40 & 75.0 & 38.20 \\
\hline 8 & 75.0 & 39.30 & 91.6 & 37.00 \\
\hline 9 & 83.3 & 38.40 & 75.0 & 38.20 \\
\hline 10 & 66.6 & 39.60 & 66.6 & 36.50 \\
\hline Avg. & 79.13 & 38.75 & 78.31 & 38.32 \\
\hline
\end{tabular}


Table 12. Experiment A: Analysis of variance of the arcsin hatchability of treatments.

\begin{tabular}{lccc}
\hline Source & df & MS & $f$ \\
Treatments & 1.0 & 3.646 & 0.041 \\
Error & 18.0 & 86.98 & \\
Total & 19.0 & &
\end{tabular}

Table 13. Experiment A: Analysis of variance of mean hatching weight of chicks.

\begin{tabular}{lccc}
\hline Source & $\mathrm{d}$ & MS & f \\
Treatments & 19.0 & 9.63 & 1.126 \\
Error & 169.0 & 8.55 & \\
Total & 188.0 & &
\end{tabular}


Table 14. Experiment A: Nean body weight and weight gains.

\begin{tabular}{|c|c|c|c|c|c|c|}
\hline \multirow[b]{2}{*}{ Group } & \multicolumn{3}{|c|}{ Body weight } & \multicolumn{3}{|c|}{ Weight gain } \\
\hline & $\begin{array}{l}\text { Initial } \\
\text { weight }\end{array}$ & $\begin{array}{l}2 \text { week } \\
\text { weight }\end{array}$ & $\begin{array}{l}4 \text { week } \\
\text { weight }\end{array}$ & $0-2$ weeks & 2-4 weeks & $0-4$ weeks \\
\hline \multicolumn{7}{|l|}{ Control } \\
\hline 1 & 39.30 & 110.10 & 248.00 & 70.80 & 137.90 & 208.60 \\
\hline 2 & 38.00 & 117.00 & 253.10 & 79.00 & 136.00 & 217.80 \\
\hline 3 & 38.50 & 114.00 & 252.90 & 75.50 & 138.90 & 213.10 \\
\hline 4 & 38.00 & 112.20 & 247.10 & 73.40 & 143.30 & 208.30 \\
\hline 5 & 38.70 & 106.30 & 238.90 & 68.10 & 132.60 & 200.90 \\
\hline 6 & 39.30 & 122.50 & 247.50 & 70.90 & 143.30 & 208.30 \\
\hline 7 & 38.40 & 115.20 & 264.90 & 76.80 & 149.70 & 226.60 \\
\hline 8 & 39.30 & 115.10 & 261.80 & 76.80 & 145.70 & 222.40 \\
\hline 9 & 38.40 & 120.10 & 275.50 & 81.70 & 155.40 & 237.10 \\
\hline 10 & 39.60 & 116.00 & 258.80 & 76.40 & 142.80 & 219.10 \\
\hline \multicolumn{7}{|c|}{ Treatment } \\
\hline 1 & 36.50 & 112.00 & 254.50 & 75.50 & 142.50 & 218.00 \\
\hline 2 & 39.10 & 108.20 & 248.80 & 68.80 & 140.60 & 209.30 \\
\hline 3 & 39.00 & 114.20 & 267.60 & 74.50 & 152.80 & 227.80 \\
\hline 4 & 40.20 & 116.10 & 260.90 & 75.90 & 144.80 & 220.80 \\
\hline 5 & 39.80 & 108.70 & 239.30 & 68.80 & 130.70 & 199.50 \\
\hline 6 & 38.70 & 115.60 & 271.50 & 76.90 & 155.90 & 232.80 \\
\hline 7 & 38.20 & 103.20 & 239.60 & 65.00 & 136.30 & 201.30 \\
\hline 8 & 37.00 & 109.50 & 243.10 & 72.50 & 133.60 & 206.10 \\
\hline 9 & 38.20 & 114.10 & 243.80 & 75.90 & 131.10 & 205.90 \\
\hline 10 & 36.50 & 108.40 & 250.50 & 71.90 & 141.60 & 213.50 \\
\hline
\end{tabular}


Table 15. Experiment A: Analysis of variance of mean two week weight of chicks.

$\begin{array}{lccc}\text { Source } & \text { df } & \text { MS } & f \\ \text { Treatments } & 19 & 162.33 & 1.098 \\ \text { Error } & 161 & 147.83 & \\ \text { Total } & 180 & & \end{array}$

Table 16. Experiment A. Analysis of variance of mean four week weight of chicks.

$\begin{array}{lrrr}\text { Source } & \text { df } & \text { MS } & f \\ \text { Treatments } & 19 & 1052.18 & 1.128 \\ \text { Error } & 159 & 933.07 & \\ \text { Total } & 178 & & \end{array}$


Table 17. Experiment A: Analysis of variance of mean weight gain of chicks from day 0 to two weeks.

\begin{tabular}{lccc} 
& \multicolumn{1}{c}{ Irom day } & No & to two weeks. \\
Source & df & 154.51 & 1.163 \\
Treatments & 19 & 132.88 & \\
Error & 161 & & \\
Total & 180 & &
\end{tabular}

Table 18. Experiment A: Analysis of variance of mean weight gain of chicks from two weeks to four weeks.

$\begin{array}{lccc}\text { Source } & \text { df } & \text { NiS } & f \\ \text { Treatments } & 19 & 490.58 & 0.785 \\ \text { Error } & 159 & 624.83 & \\ \text { Total } & 178 & & \end{array}$


Table 19. Experiment A: Analysis of variance of mean weight gain of chicks from day 0 to four weeks.

$\begin{array}{lccc}\text { Source } & \text { df } & \text { MS } & f \\ \text { Treatments } & 19 & 1021.18 & 1.128 \\ \text { Error } & 159 & 904.99 & \\ \text { Total } & 178 & & \end{array}$


Table 20. Experiment A: Four week mortality

\begin{tabular}{|c|c|c|c|}
\hline \multicolumn{2}{|c|}{ Control } & \multicolumn{2}{|c|}{ Treated } \\
\hline Group & Cause of death & Group & Cause of death \\
\hline 1 & Anemia & 2 & Anemia \\
\hline 4 & Wet, colibacillosis & 3 & Starveout \\
\hline 5 & Pale, dry, anemia & 3 & Colibacillosis \\
\hline & & 3 & Dehydrated \\
\hline & & 3 & Gizzard impaction \\
\hline & & 8 & Dehydrated \\
\hline
\end{tabular}


Table 2l. Experiment $C_{8}$ Analysis of variance of mean weights of chicks surviving the treatment versus those dying after exposure to a total radiation input of 596 watt-sec per chick

\begin{tabular}{lrcc}
\hline Source & df & MS & f \\
Treatments & 1 & 8.08 & 1.201 \\
Error & 92 & 6.72 & \\
Total & 93 & &
\end{tabular}

Table 22. Experiment C: Analysis of variance of the initial weights of cockerels.

$\begin{array}{lrcc}\text { Source } & \text { df } & \text { MS } & f \\ \text { Treatments } & 2 & 73.46 & 9.707^{*} \text { \% } \\ \text { Error } & 153 & 7.57 & \\ \text { Total } & 155 & & \end{array}$


Table 23. Experiment $C:$ Actual weights and weight gains of chicks

\begin{tabular}{|c|c|c|c|}
\hline & Control & 4 sec. & 6 sec. \\
\hline Initial weight & 33.30 & 35.40 & 35.40 \\
\hline I week weight & 56.20 & 54.90 & 51.75 \\
\hline I week weight gain & 22.90 & 19.50 & 16.30 \\
\hline 2 week weight & 99.80 & 95.80 & 90.00 \\
\hline 2 week weight gain & 66.40 & 60.50 & 54.50 \\
\hline Weight gain 1st to 2nd week & 43.30 & 40.50 & 37.36 \\
\hline 3 week weight & 165.00 & 157.80 & 151.38 \\
\hline 3 week weight gain & 131.70 & 122.50 & 115.90 \\
\hline Weight gain 2nd to $3 \mathrm{rd}$ week & 64.70 & 62.00 & 61.50 \\
\hline
\end{tabular}


Table 24. Experiment $C_{8}$ Analysis of variance of the actual chick weights at one week of age.

\begin{tabular}{lrrc}
\hline Source & df & NS & $f$ \\
Treatments & 2 & 270.34 & $4.875 \%$ \\
Error & 152 & 55.45 & \\
Total & 154 & &
\end{tabular}

Table 25. Experiment $C_{8}$ Analysis of variance of the first week weight gains of chicks.

\begin{tabular}{lrrc} 
Source & \multicolumn{1}{c}{ df } & \multicolumn{1}{c}{ MS } & $f$ \\
Treatment & 2 & 562.59 & $13.257 * \%$ \\
Error & 152 & 42.48 & \\
Total & 154 & &
\end{tabular}


Table 26. Experiment $C:$ Analysis of variance of weights of cockerels at two weeks of age.

\begin{tabular}{lrrc}
\hline Source & df & \multicolumn{1}{c}{ MS } & \multicolumn{1}{c}{} \\
Treatments & 2 & 1206.27 & $5.907 \% \%$ \\
Error & 149 & 204.22 & \\
Total & 151 & &
\end{tabular}

Table 27. Experiment C: Analysis of variance of weight gains of cockerels to two weeks.

\begin{tabular}{lrrc} 
& \multicolumn{1}{c}{ df } & \multicolumn{1}{c}{ MS } & \multicolumn{1}{c}{} \\
Treatments & 2 & 1779.42 & $9.845 \%$ \\
Error & 149 & 180.75 & \\
Total & 151 & &
\end{tabular}


64

Table 28. Experiment C: Analysis of variance of weight gains of cockerels

during the second week.

\begin{tabular}{lrrr} 
Source & df & \multicolumn{1}{c}{ NiS } & $f$ \\
Treatments & 2 & 444.93 & $4.633 *$ \\
Error & 149 & 96.03 & \\
Total & 151 & &
\end{tabular}

Table 29. Experiment $C_{8}$ Analysis of variance of weights of cockerels at

three weeks of age.

\begin{tabular}{lrrr} 
Source & df & \multicolumn{1}{c}{ MS } & $f$ \\
Treatments & 2 & 2314.69 & $3.460 \%$ \\
Error & 147 & 668.23 & \\
Total & 149 & &
\end{tabular}


Table 30. Experiment C: Analysis of variance of weight gain of cockerels to three weeks of age.

\begin{tabular}{lrrr}
\hline Source & df & \multicolumn{1}{c}{ MS } & $f$ \\
Treatments & 2 & 3120.79 & $5.047 \%$ \\
Error & 148 & 618.38 & \\
Total & 150 & &
\end{tabular}

Table 31. Experiment C: Analysis of variance of weight gain of cockerels during the third week of age.

$\begin{array}{lrcc}\text { Source } & \text { df } & \text { MS } & f \\ \text { Treatments } & 2 & 201.49 & .8560 \\ \text { Error } & 148 & 235.38 & \\ \text { Total } & 150 & & \end{array}$


Table 32. Experiment D: Mortality of $\mathrm{Hy}-$ Iine layers

Control Treated

Cause of death Number died Number died

Nareks disease 13

Wing trauma

1

No visible lesions

2

1

Emmaciation

1

Gizzard impaction

1

1

Peritonitis

1

TOTAI

19

2 
Table 33. Hen day production of control and treatment groups in Experiment D. 100 day laying period August 1。 1973 to November $8,1973$.

\begin{tabular}{|c|c|c|c|c|c|c|}
\hline \multirow[b]{2}{*}{ Month } & \multicolumn{3}{|c|}{ Control } & \multicolumn{3}{|c|}{ Treated } \\
\hline & Eggs & $\begin{array}{l}\text { Hen } \\
\text { days }\end{array}$ & $\begin{array}{c}\text { Hen } \\
\text { day \% }\end{array}$ & Eggs & $\begin{array}{l}\text { Hen } \\
\text { days }\end{array}$ & $\begin{array}{c}\text { Hen } \\
\text { day \% }\end{array}$ \\
\hline$\overline{\text { August }}$ & 763 & 1209 & $\overline{63.11}$ & 940 & 1705 & 55.0 \\
\hline September & 677 & 1080 & 62.69 & 1069 & 1650 & 64.78 \\
\hline October & 710 & 1116 & 63.00 & 1159 & 1674 & 69.20 \\
\hline $\begin{array}{c}\text { November } \\
1-8\end{array}$ & 162 & 288 & 56.25 & 276 & 432 & 63.89 \\
\hline Total & 2312 & 3693 & 62.60 & 3444 & 5461 & 63.06 \\
\hline
\end{tabular}

Table 34. Hatchability of eggs from treatment and control birds in Experiment $D$. Test 2 and test 3

$\begin{array}{lll} & \text { Test 2 } & \text { Test 3 } \\ \text { Control } & 77.36 \% & 79.10 \% \\ \text { Treated } & 80.17 \% & 85.15 \%\end{array}$


Table 35. Experiment E: Mortality in Hy-Iine stock

\begin{tabular}{|c|c|c|c|c|}
\hline \multirow[b]{3}{*}{ Cause of death } & \multicolumn{4}{|c|}{ Number of chicks died } \\
\hline & \multicolumn{2}{|c|}{$0-4$ weeks } & \multicolumn{2}{|c|}{$5-20$ weeks } \\
\hline & Control & Treated & Control & Treated \\
\hline Bad legs & 1 & & & 2 \\
\hline Dehydration & 1 & 1 & & 2 \\
\hline Drowned & 1 & & & \\
\hline Intestinal obstruction & 1 & & & \\
\hline Infected yolk sac & & 1 & & \\
\hline Picked & & 2 & & \\
\hline Thermal leg injuxy & & 12 & & \\
\hline Gizzard impaction & & 1 & 18 & 10 \\
\hline Mareks & & & 47 & 49 \\
\hline Coccidiosis & & & 1 & 3 \\
\hline No visible lesions & & & 2 & 3 \\
\hline Fatty liver & & & 1 & \\
\hline Emaciated & & & & 1 \\
\hline Total & 4 & 17 & 69 & 70 \\
\hline
\end{tabular}


Table 36. Experiment $\mathrm{E}:$ Mortality in Shaver stock

\begin{tabular}{|c|c|c|c|c|}
\hline \multirow[b]{3}{*}{ Cause of death } & \multicolumn{4}{|c|}{ Number of chicks died } \\
\hline & $0=4$ & weeks & $5-20$ & weeks \\
\hline & Control & Treated & Control & Treated \\
\hline Picking & 2 & 6 & & \\
\hline Infected yolk sac & & 5 & & \\
\hline Thermal leg injury & & 5 & & \\
\hline Gizzard impaction & & 1 & 6 & 8 \\
\hline Enteritis & & 1 & & 1 \\
\hline Omphalitis & & 1 & & \\
\hline Starveout & & 1 & & \\
\hline No visible lesions & & 1 & 3 & 2 \\
\hline Mareks & & & 27 & 22 \\
\hline Dehydration & & & 1 & 1 \\
\hline Dislocated femur & & & & 1 \\
\hline Total & 2 & 21. & 37 & 35 \\
\hline
\end{tabular}


Table 37. Experiment E: Mortality in the Babcock stock

\begin{tabular}{|c|c|c|c|c|}
\hline \multirow[b]{3}{*}{ Cause of death } & \multicolumn{4}{|c|}{ Number of chicks died } \\
\hline & $0-4$ & weeks & $5-20$ & weeks \\
\hline & Control & Treated & Control & Treated \\
\hline Dehydration & & 1 & & 2 \\
\hline Leg injuries & & 2 & & \\
\hline Mareks & & & 84 & 55 \\
\hline Gizzard impaction & & & 14 & 9 \\
\hline Cripple & & & 1 & 1 \\
\hline Anemia & & & & 1 \\
\hline Coccidiosis & & & & 1 \\
\hline No visible lesions & & & & 2 \\
\hline Trauma & & & 2 & \\
\hline Total & 0 & 3 & 101 & 71 \\
\hline
\end{tabular}


Table 38. Experiment E\& Analysis of variance of overall mortality

\begin{tabular}{lrrrc}
\hline & df & SS & NS & $f$ \\
Total & 5 & 3049 & & \\
Treatment & 1 & 160 & 160 & 1.094 \\
Blocks & 2 & 2596.5 & 1298.25 & 8.870 \\
Error & 2 & 292.5 & 146.25 &
\end{tabular}

Table 39. Experiment E: Analysis of variance of mortality due to Nareks disease

\begin{tabular}{lrrrc}
\hline & df & SS & MS & f \\
Total & 5 & 2462 & & \\
Treatment & 1 & 171.0 & 171.0 & 1.295 \\
Blocks & 2 & 2027.0 & 1013.5 & 7.678 \\
Error & 2 & 264.0 & 132 &
\end{tabular}


Table 40. Experiment F\& Mean Haugh Unit values
in treated and control eggs
according to time and
temperature of storage

\begin{tabular}{cccc}
\hline Cold eggs & $\frac{\text { Control }}{84.13}$ & $\frac{\text { Treated }}{89.33}$ \\
\hline Day & 0 & 83.79 & 83.38 \\
$"$ & 2 & 76.12 & 73.75 \\
$"$ & 7 & 76.25 & $68.38 \%$ \\
$" 14$ & 69.88 & 70.29 \\
$"$ & 21 & 66.79 & 72.83 \\
$"$ & 35 & 66.63 & 70.21 \\
" 42 & &
\end{tabular}

Warm eggs

\begin{tabular}{lrll}
\hline Day & 2 & 67.71 & 66.79 \\
$"$ & 5 & 64.68 & 62.66 \\
$"$ & 8 & 58.42 & 60.88 \\
$" 12$ & 52.58 & 44.79 \\
$" 15$ & 46.54 & 41.92
\end{tabular}


Table 41. Experiment G: Mean Haugh Unit values

in treated and control eggs according to time and temperature of storage

\begin{tabular}{cccc}
\hline Cold eggs & $\frac{\text { Control }}{81.83}$ & $\frac{\text { Treated }}{77.92}$ \\
\hline Day & 0 & 80.75 & 80.58 \\
$"$ & 2 & 76.75 & 73.00 \\
$" \quad 7$ & 76.42 & 74.75 \\
$" 14$ & 76.71 & 76.79 \\
$" 21$ & 75.88 & 71.21 \\
$" 28$ & 69.38 & 69.88 \\
$"$ & 35 & 69.33 & 68.58
\end{tabular}

Warm eggs

$\begin{array}{crll}\text { Day } & 2 & 68.50 & 71.21 \\ " & 5 & 57.83 & 61.51 \\ " & 8 & 61.29 & 56.00 \\ " 12 & 58.38 & 49.88 * \\ " 15 & 41.63 & 37.54\end{array}$


Table 42. Experiment F: Analysis of variance of Haugh Unit values of cold stored treated and control eggs

\begin{tabular}{|c|c|c|c|c|c|}
\hline \multirow[t]{4}{*}{ Day } & $0:$ & Source & $d f$ & MS & $f$ \\
\hline & & Treatments & 1 & 162.76 & $6.59 \%$ \\
\hline & & Error & 22 & 24.67 & \\
\hline & & Total & 23 & & \\
\hline \multirow[t]{4}{*}{ Day } & 2: & Source & $d f$ & MS & $f$ \\
\hline & & Treatments & 1 & 1.04 & 0.0196 \\
\hline & & Error & 22 & 53.04 & \\
\hline & & Total & 23 & & \\
\hline \multirow[t]{4}{*}{ Day } & $7:$ & Source & $d f$ & MS & $f$ \\
\hline & & Treatments & 1 & 33.84 & 0.549 \\
\hline & & Error & 22 & 61.67 & \\
\hline & & Total & 23 & & \\
\hline \multirow[t]{4}{*}{ Day } & 14: & Source & $d f$ & MS & $f$ \\
\hline & & Treatments & 1 & 372.09 & $6.98 *$ \\
\hline & & Error & 22 & 53.09 & \\
\hline & & Total & 23 & & \\
\hline \multirow[t]{4}{*}{ Day } & 21: & Source & $d f$ & MS & $f$ \\
\hline & & Treatments & 1 & 1.04 & 0.020 \\
\hline & & Error & 22 & 52.81 & \\
\hline & & Total & 23 & & \\
\hline \multirow[t]{4}{*}{ Day } & $35:$ & Source & $d f$ & MS & $f$ \\
\hline & & Treatments & 1 & 219.01 & 4.020 \\
\hline & & Error & 22 & 54.54 & \\
\hline & & Total & 23 & & \\
\hline \multirow[t]{4}{*}{ Day } & $42:$ & Source & $d f$ & MiS & $f$ \\
\hline & & Treatments & 1 & 77.04 & 2.42 \\
\hline & & Error & 22 & 31.88 & \\
\hline & & Total & 23 & & \\
\hline
\end{tabular}


Table 43. Experiment F: Analysis of variance of Haugh Unit values of warm stored treated and control eggs

\begin{tabular}{|c|c|c|c|c|c|}
\hline \multirow[t]{4}{*}{ Day } & $2:$ & Source & $d f$ & MS & f \\
\hline & & Treatments & 1 & 5.04 & 0.092 \\
\hline & & Error & 22 & 54.75 & \\
\hline & & Total & 23 & & \\
\hline \multirow[t]{4}{*}{ Day } & 5: & Source & $d f$ & MS & $f$ \\
\hline & & Treatments & 1 & 23.31 & 0.346 \\
\hline & & Error & 21 & 67.28 & \\
\hline & & Total & 22 & & \\
\hline \multirow[t]{4}{*}{ Day } & $8:$ & Source & $d f$ & MS & $f$ \\
\hline & & Treatments & 1 & 36.26 & 0.402 \\
\hline & & Error & 22 & 90.16 & \\
\hline & & Total & 23 & & \\
\hline \multirow[t]{4}{*}{ Day } & 12: & Source & $d f$ & IVS & $f$ \\
\hline & & Treatments & 1 & 364.26 & 4.112 \\
\hline & & Error & 22 & 88.57 & \\
\hline & & Total & 23 & & \\
\hline \multirow[t]{4}{*}{ Day } & 15: & Source & df & MS & $f$ \\
\hline & & Treatments & 1 & 128.34 & 3.692 \\
\hline & & Error & 22 & 34.75 & \\
\hline & & Total & 23 & & \\
\hline
\end{tabular}


Table 44. Experiment G: Analysis of variance of Haugh Unit values of cold stored treated and control eggs

\begin{tabular}{|c|c|c|c|c|c|}
\hline \multirow[t]{4}{*}{ Day } & $0:$ & Source & $d f$ & MS & $f$ \\
\hline & & Treatments & 1 & 92.040 & 2.236 \\
\hline & & Error & 22 & 41.160 & \\
\hline & & Total & 23 & & \\
\hline \multirow[t]{4}{*}{ Day } & $2:$ & Source & $d f$ & MS & $f$ \\
\hline & & Treatments & 1 & 1.670 & $0.00 ?$ \\
\hline & & Error & 22 & 22.780 & \\
\hline & & Total & 23 & & \\
\hline \multirow[t]{4}{*}{ Day } & $7:$ & Source & $d f$ & MiS & $f$ \\
\hline & & Treatments & 1 & 84.380 & 2.111 \\
\hline & & Error & 22 & 39.960 & \\
\hline & & Total & 23 & & \\
\hline \multirow[t]{4}{*}{ Day } & 14: & Source & $d f$ & MiS & $f$ \\
\hline & & Treatments & 1 & 16.670 & .599 \\
\hline & & Error & 22 & 27.830 & \\
\hline & & Total & 23 & & \\
\hline
\end{tabular}


Table 44 (Continued)

\begin{tabular}{llrrr} 
Day 21: & Source & df & \multicolumn{1}{c}{ MS } & $f$ \\
& Treatments & 1 & .042 & 0.001 \\
& Error & 22 & 40.790 & \\
Total & 23 & & \\
Day 28: & Source & df & MS & $f$ \\
& Treatments & 1 & 130.670 & 3.766 \\
& Error & 22 & 34.695 & \\
& Total & 23 & & \\
Day 35: & Source & df & MS & 1 \\
& Treatments & 1 & 1.500 & 0.721 \\
& Error & 22 & 20.778 & \\
& Total & 23 & & $f$ \\
Day 42: & Source & df & MiS & \\
& Treatments & 1 & 3.38 & 0.100 \\
& Error & 22 & 33.62 &
\end{tabular}


Table 45. Experiment G: Analysis of variance of Haugh Unit values of warm stored treated and control eggs

\begin{tabular}{|c|c|c|c|c|c|}
\hline \multirow[t]{4}{*}{ Day } & $2:$ & Source & $d f$ & MS & $f$ \\
\hline & & Treatments & 1 & 44.01 & 1.006 \\
\hline & & Error & 22 & 43.76 & \\
\hline & & Total & 23 & & \\
\hline \multirow[t]{4}{*}{ Day } & 5: & Source & $d f$ & MS & $f$ \\
\hline & & Treatments & 1 & 85.51 & 1.877 \\
\hline & & Error & 22 & 43.95 & \\
\hline & & Total & 23 & & \\
\hline \multirow[t]{4}{*}{ Day } & $8:$ & Source & $d f$ & MS & $f$ \\
\hline & & Treatments & 1 & 168.01 & 2.826 \\
\hline & & Error & 22 & 59.44 & \\
\hline & & Total & 23 & & \\
\hline \multirow[t]{4}{*}{ Day } & 12: & Source & $d f$ & MS & $f$ \\
\hline & & Treatments & 1 & 433.50 & 5.357 \\
\hline & & Error & 22 & 80.91 & \\
\hline & & Total & 23 & & \\
\hline \multirow[t]{4}{*}{ Day } & 15: & Source & $d f$ & MS & $f$ \\
\hline & & Treatments & 1 & 100.040 & 1.522 \\
\hline & & Error & 22 & 65.70 & \\
\hline & & Total & 23 & & \\
\hline
\end{tabular}


Table 46. Experiments $\mathrm{H}, \mathrm{I}$ and $\mathrm{J}$ hatchability of eggs

\begin{tabular}{ccccc}
\hline Experiment & Control & $\frac{\begin{array}{c}\text { Microwave } \\
\text { treated } \\
\text { contaminated }\end{array}}{\text { Contaminated }}$ \\
$\mathrm{H}$ & $63.6,70.9(67.25)$ & $83 \%$ & $31 \%$ \\
$\mathrm{I}$ & $82.2 \%$ & $81.1 \%$ & $82.2 \%$ \\
$\mathrm{~J}$ & $70.0 \%$ & $75.5 \%$ & $66.0 \%$
\end{tabular}




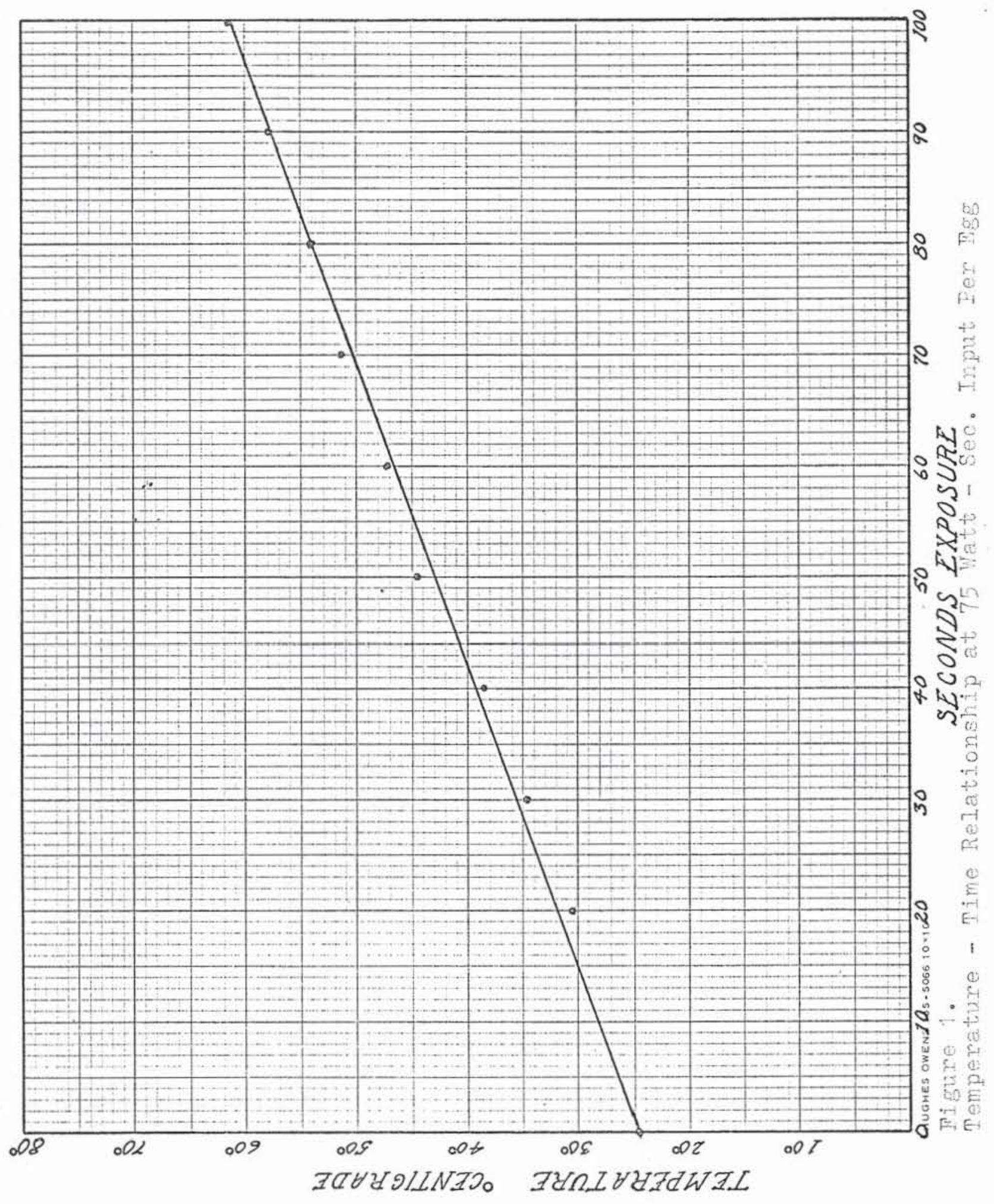




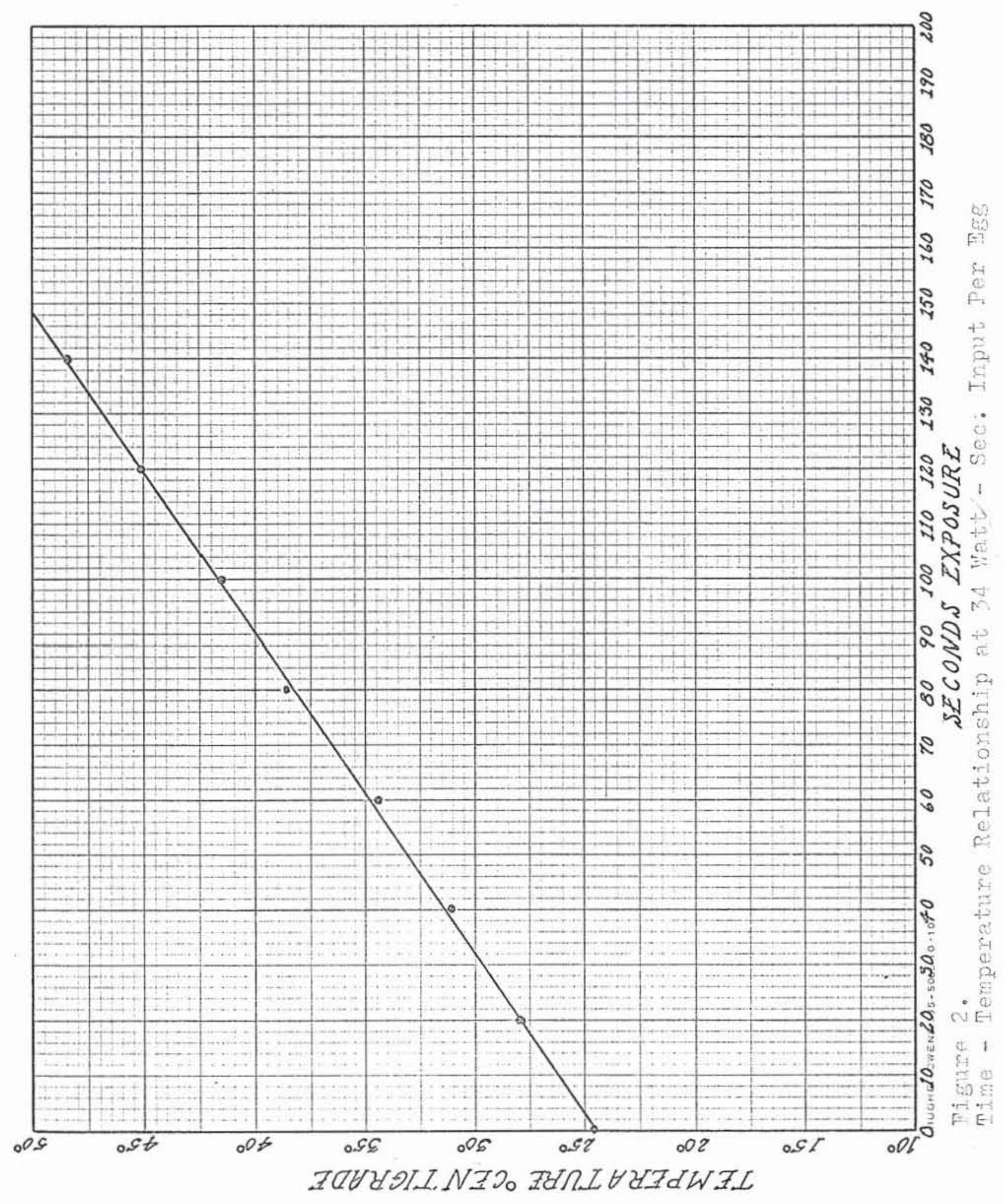




\section{REFERENCES}

Bell, D. J. and Freeman, B. M. 1971. Physiology and biochemistry of the domestic fowl. Vol. 2. P. 1122, Academic Press.

Bilbrough, J. 1961. Food sterilization by microwave ration. Non ionizing radiation. Sept, 1969, 70-72.

Hills, Gordon A. 1971. The effect of microwave radiation on the embryonic development and post embryonic growth in chickens and turkeys. Master of Science Thesis, University of Nanitoba, Department of Animal Science.

Kondra, P. A., Smith, W. K., Hodgson, G. C., Bragg, D. B., Gavora, J., Hamid, M. A, K, and Boulanger, R。 J。 1970. Growth and reproduction of chickens subjected. to microwave radiation. Can. J. Anim. Sci. 50: 639-644.

Kondra, P. A., Hamid, M. A. and Hodgson, G. C. 1972. Effects of microwave radiation on growth and reproduction of two stocks of chickens. Can. J. Anim. Sci. 52: $317-320$ 。

McAfee, R. D., Nieset, R. T., Baus, R, Friedman, J. J., Hyde, A. S, and Flemming, J. D. Review of the work conducted at Tulane University in Proceedings of the Second Tri-Service Conference on Biological Effects of Microwave Energy, ASTIA Document, No AD 131-477, 1958. 
MicAfee, Robert D. 1972. Low power density behavior effects of microwave irradiation of experimental animals: Real or artifact? Journal of Microwave Power 7 (2): $83-85$.

McAfee, Robert D., Braus, R. Jr., Fleming, J. Jr. 1973. The effect of $2450 \mathrm{MHz}$ microwave irradiation on the growth of mice. Journal of Microwave Power 8 (1): $111-116$.

Milroy, William C. and Michaelson, Sol. M. 1971. Biological effects of microwave radiation. Health Physics 20: 567-75.

Milroy, William C, and Michaelson, Sol, M. 1972. Microwave cataractogenesis: A critical review of the literature. Aerospace Medicine 43 (1): 67-75. Romanoff, Alexis L. 1967. Biochemistry of the avian embryo. John Wiley and Sons. Romero-Sierra, C. and Tanner, J. A. 1970. Microwave radiation and egg production in chickens. Proceedings of the 1970 International Microwave Power Symposium.

Rosen, Carl-Gustaf. 1972. Effects of microwaves on food and related materials. Food Technology, July 1972. Schwan, H. P. 1969. Effects of microwave radiation on tissue - a survey of basis mechanisms. Non Ionizing Radiation, June 1969, 23-32. 
Schwan, H。 P. 1972. Microwave ration: biophysical considerations and standards criteria. IEEE Transactions on Biomedical Engineering. Vol. BNE-19 \#4, 304-312. Takashma, S. 1969. Dielectric properties of proteins. I. dielectric relaxation. In "Physical principles and Techniques of Protein Chemistry". Part A。 ed. Leach, S. J. p. 291. Academic Press, New York。 Tanner, JoA. 1966. Effect of microwave radiation on birds. Nature Vol. 210: 636. Tanner, J. A., Romero-Sierra, C。, Davie, S. J. 1969. The non-thermal effects of microwaves on birds. Nature Vol. 216: 1139.

Tanner, J.A., Romero-Sierra, C., Davie, S. J. 1967. The effects of microwaves on birds. Journal of Microwave Power 4 (2): 122-128.

Tanner, J.A., Romero-Sierra, C. 1970. Microwave radiation and egg production in chickens. Proceedings of the 5th International Symposium, International Microwave Institute, Scheveningen, The Netherlands. Van Ummerson, Clare. 1963. The effect of 2450 mc radiation on the development of the chick embryo. Biological Effects of Microwave Radiation: 201-219. Plenum Press, New York. 